\title{
KINETICS OF OXIDATION OF DEHYDRATED FOOD \\ AT LOW OXYGEN PRESSURES
}

by

Louis J. Kacyn

B.A. - Psychology and B.S. - Food Science

University of Illinois

(Urbana, Illinois, 1977 and 1980, respectively)

Submitted in Partial Fulfillment of the Requirements for the Degrees of Master of Science in Food Science and Technology, and Master of Science in Chemical Engineering

at the

MASSACHUSETTS INSTITUTE OF TECHNOLOGY

May 1983

oMassachusetts Instityzte of Teçhology, 1983

Signature redacted

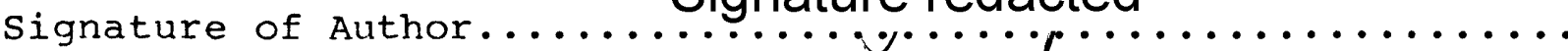

Signature $\left.\right|^{\text {Department of Nutrition and Food Science }}$
May 12,1983

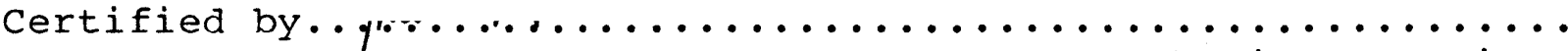

Signaturē redacted

Thesis Supervisor

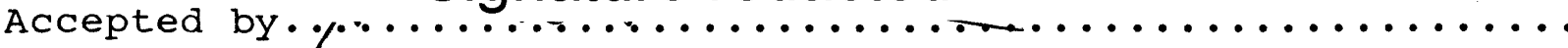

Chairman, Departmental Committee on Graduate Students, Department of Nutrition and Food science Signature redacted

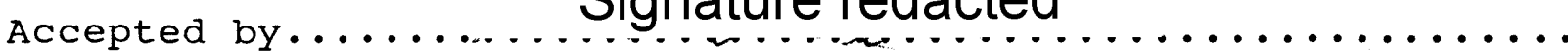

Chairman, Departmental Committee on Graduate Students, Department of Chemical Engineering

\section{Archlves}

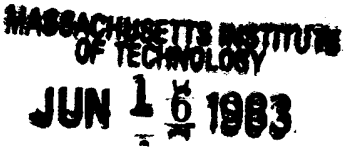

Lenchang 


\title{
KINETICS OF OXIDATION OF DEHYDRATED FOOD \\ AT LOW OXYGEN PRESSURES
}

\author{
by \\ Louis J. Kacyn
}

Submitted to the Department of Nutrition and Food Science and the Department of Chemical Engineering on May 27, 1983 in partial fulfillment of the requirements for the degree of Master of Science.

\section{ABSTRACT}

An apparatus for the measurement of adsorbed/entrapped oxygen held by dehydrated powdered products was developed and is described in detail. The method works on the principle of sample solubilization in deaerated water with compression of the liberated gases into a calibrated chamber containing an oxygen probe. When tested on nonfat dry milk, the coefficient of variation for the method is $20 \%$.

Kinetic studies using this apparatus were performed on a model system consisting of methyl linoleate dispersed on Avicel microcrystalline cellulose and nonfat dry milk at headspace oxygen concentrations of $0.52 \%$ - 10.69\%. Excellent correlation was found in the model system between diene conjugation values and oxygen uptake as measured by the apparatus. Correlation coefficients between the two methods were in the range .987 .997 .

Bimolecular kinetics were found to apply to both the model system and the milk-lipid system with $\mathrm{K}_{\mathrm{B}}{ }^{\prime} \mathrm{s}$ within the range expected from studies done by previous workers at higher $\mathrm{O}_{2}$ pressures. The $\mathrm{K}_{\mathrm{B}}$ 's for the cellulose model system were found to be 5 to 6 times greater than those in the milk based system. This was due partly to encapsulation of lipids in the milk during preparation and partly due to smaller surface area in the milk-based system.

Mathematical models for the oxidation rate constants as a function of headspace $\mathrm{O}_{2}$ concentrations were derived for the two systems.

Thesis Supervisor: Dr. Marcus Karel Title: Professor of Food Engineering 


\section{DEDICATION}

This thesis is dedicated, with much love, to my parents, Mario and Clara Kacyn who, by example, taught me the value of ideas, knowledge, and education while instilling in me a deep respect for the people from whom these are derived. 


\section{ACKNOWLEDGEMENTS}

I wish to express my gratitude to Professor Marcus Karel for his support and thoughtful guidance throughout this work. Dr. Karel's remarkable ability to quickly evaluate a given situation, identify the difficulties involved, and provide viable directions to pursue is awe-inspiring. It was an honor to work with him.

My thanks are also due to Dr. Israel (Sam) Saguy for his help and advice during the summers that he visited MIT. The guidance I received from him in general, and specifically regarding the construction and use of the sorbed oxygen apparatus described herein was invaluable.

My deep appreciation and love also go to my parents-inlaw, Nathan and Esther Wagner who, with their keen insight and thoughtful questions helped make the path to the completion of this work a steadier and more direct one.

Most of all, I wish to thank my loving wife Susan. Her uncanny ability to keep our lives in order, be a wonderful mother, succeed so admirably in her work, and provide me with the love and support I needed during the last three years made this possible. 
Last, but certainly not least, I wish to thank little Robin Eve. Although she asked for none of this, her pure, unabashed love gave me the added perspective to realize this goal. 
TABLE OF CONTENTS

Page

Title Page

Abstract

Dedication

Table of Contents

List of Figures

1. Introduction

2. Literature Review 14

2.1. Oxygen Uptake Measurement 14

2.2. Adsorbed/Entrapped Oxygen 20

2.3. Oxygen Uptake of Oxidizing Lipids as a Function 26 of Oxygen Partial Pressure

2.3.1. Pure Compounds

2.3.2. Model Systems

2.3.3. Food Systems

3. Materials and Methods

3.1. Adsorbed/Entrapped Oxygen Measurement

3.1.2. Apparatus

3.1.3. Procedure

a. Deaeration of the water 39

b. Calibration of the Probes

c. Evacuation of the system

d. Solubilization of the Sample 12 14

\section{(1)}

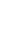
.

\section{(6} $(10$ 
e. Compression of the Headspace Gas

f. Measurement of the Gaseous Oxygen

42

g. Measurement of Dissolved Oxygen

3.2. Headspace Gas Measurement

3.3. Diene Conjugaton Analysis 43

3.4. Sorption Isotherm Preparation 44

3.5. Determination of Flask and Sample Volumes 44

3.6. Preparation of Samples 45

3.6.1. Model System 45

3.6.2. Milk-Lipid System 46

3.7. Filling the Flasks with Various $\mathrm{O}_{2} / \mathrm{N}_{2}$ Mixtures 47

3.8. Problems Encountered 47

3.8.1. Leakages 48

3.8.2. Calibration of the Probe 48

3.3.3. Measurement of Dissolved Oxygen 48

3.8.4. Glass Compatibility and the sorbed 49

Oxygen Apparatus

4. Results and Discussion 50

4.1. Oxygen Adsorbed/Entrapped in Nonfat Dry Milk 50

4.2. Model System Studies 52

4.2.1. Correlation of Oxygen Uptake Values 53 with Diene Conjugation

4.2.2. Kinetic Studies 59

4.2.2.1. Oxygen Uptake vs Time at 59

$0.528,1.05 \%, 2.178$

and $5.49 \%$ 
4.2.2.2. Rate Constants as a Function

of Percent Oxygen in the

the Headspace for the Same

Batch of Model system

4.3. Milk System Studies

4.3.1. Kinetic Studies

4.4. Comparison of Model System and Milk System Results

4.4.1. Encapsulation Effects

4.4.2. Surface Area Effects

5. Conclusions

6. Suggestions for Further Work

7. Appendices

Appendix A

Appendix B

Appendix C

8. Bibliography 99

9. List of Symbols

106 


\section{LIST OF TABLES}

No.

Title

$\underline{\text { Page }}$

1. Values of $\mathrm{O}_{2}$ adsorbed/entrapped in nonfat dry milk.

2. Correlation coefficients between $\mathrm{O}_{2}$ uptake and diene conjugation in an Avicel-methyl linoleate model system.

3. Rate constants and $8 \mathrm{O}_{2}$ concentrations for various batches of model system.

4. Rate constants and $\% \mathrm{O}_{2}$ concentrations for the same batch of model system.

5. Rate constants and $8 \mathrm{O}_{2}$ concentrations for the milk 1 ipid system.

6. Comparison between bimolecular rate constants reported in the literature and those observed experimentally.

7. Isotherm data for determination of B.E.T. paremeters. 


\section{LIST OF FIGURES}

No.

Title

Page

1. Apparatus for determination of adsorbed/entrapped oxygen .

2. Model system oxidation at $0.52 \% \mathrm{O}_{2}$. 54

3. Model system oxidation at $1.05 \% \mathrm{O}_{2}$. 55

4. Model system oxidation at 2.17 용 $\mathrm{O}_{2}$. 56

5. Reciprocal plot of $1 / \mathrm{K}$ vs. $1 / \% \mathrm{O}_{2}$ (different batches).

6. Oxidation of an Avicel-lipid model system.

7. First order plot of model system oxidation. 64

8. Reciprocal plot of $1 / \mathrm{K}$ vs. $1 / 8 \mathrm{O}_{2}$ (same batch). 66

9. First order constant as a function of $8 O_{2}$ (model 68 system)

10a. Milk-methyl linoleate system oxidation - lst run.

10b. Milk-methyl linoleate system oxidation - 2nd run. 72

1la. First order plot of milk system oxidation - lst run. 73

11b. First order plot of milk system oxidation - 2nd run. 74

12. Reciprocal plot of $1 / \mathrm{K}$ vs. $1 / \% \mathrm{O}_{2}$ (milk system). 76

13. First order constant as a function of $z \mathrm{O}_{2}$ (milk system).

14. First order constant as a function of $\frac{\mathrm{g}}{\mathrm{O}} \mathrm{O}_{2}$ (model and milk systems).

15. Comparison of dry and humidified milk-lipid system. 
16. Nonfat dry milk isotherm $-37^{\circ} \mathrm{C}$. 95

17. B.E.T. isotherm $-37^{\circ} \mathrm{C}$. 


\section{INTRODUCTION}

Given the complex nature of deteriorative reactions in foods, identifying and quantifying the causal factors leading to undesirable changes can be very difficult, if not impossible to do.

Lipid oxidation is a major cause of quality deterioration in dehydrated foods containing fats or oils with unsaturated fatty acid moities. Oxygen can react with these fatty acids leading to the formation of low molecular weight compounds with objectionable odors detectable in the parts per million or parts per billion ranges (Labuza, 1971).

A common method of controlling the oxidation reaction is to deplete the concentration of oxygen in the headspace of the food package by vacuum or nitrogen packing. Industrially, the concentration of oxygen is never decreased to zero by these methods and residual oxygen adsorbed or entrapped within the food material itself may be present. This small amount of oxygen present in the food package may be responsible for initiating oxidation. Since lipid oxidation occurs via a chain reaction mechanism, initiation of the reaction must be avoided to maintain product quality.

The work in this thesis is aimed at the goal of quantifying the effect of low concentrations of headspace oxygen on the rate of reaction of methyl linoleate dispersed on Avicel microcrystalline cellulose and on nonfat dry milk at the 
following conditions: Temperature $=37^{\circ} \mathrm{C}, \mathrm{a}_{\mathrm{w}}=\mathrm{dry}$, initial Iinoleate concentration $\left(C_{0}\right)=0.1 \mathrm{~g}$ oil $/ \mathrm{g}$ powder, and headspace oxygen concentrations of $0.52-10.69 \& \mathrm{O}_{2}$. In order to study the reaction at such conditions, we constructed an apparatus capable of measuring the low headspace oxygen concentrations as well as the adsorbed/entrapped oxygen. 


\section{LITERATURE REVIEW}

In this literature review three areas affecting oxidation of lipids in foods are reviewed. Firstly, available methods of oxygen uptake determination are examined. Secondly, adsorbed/entrapped oxygen in dehydrated systems, method of measurement of this gas, and a comparison of these methods is discussed. Lastly, the broader question of the effect of oxygen pressure on oxidation of foods, model systems, and of pure compounds is reviewed.

2.1. Oxygen Uptake Measurement

By far the most popular method of direct oxygen uptake determination is the Warburg manometric technique. This is a constant volume method in which the pressure inside the reaction flask changes as oxygen is consumed. The pressure differential is observed on a manometer connected to the flask on one arm and the atmosphere on the other. Variations in ambient temperature are controlled by immersion of the flasks in a controlled temperature bath and atmospheric pressure variations accounted for by control manometers. Gases evolved during the progress of the reaction will give erroneous results if not accounted for. One such gas is carbon dioxide which can be absorbed in alkali. Other gases may be harder to correct for. 
Umbreit et al. (1964) is a standard reference for work with the Warburg manometer and should be consulted for application to specific food systems. The Warburg method is useful at high oxygen concentrations and many authors have described their work with this apparatus (Labuza et al., 1968; Labuza et al., 1971; Maloney et al., 1966).

To study oxygen uptake at low partial pressures of oxygen, the Warburg method has several drawbacks which make its use much more tedious. If the oxidative reaction is slow, the method is not sensitive enough to provide data in a short time. Conversely, if the reaction if fast, the oxygen concentration inside the small flask will also change quickly, thus affecting the rate of the reaction and nullifying a static experiment requiring a known (and somewhat constant) headspace oxygen concentration. Karel (1960) modified the Warburg apparatus for use of low $\mathrm{O}_{2}$ pressures by using vacuum as the reference instead of atmosphere pressure. Marcuse and Fredriksson (1968) and Marcuse et al. (1964) also describe a modification to the Warburg apparatus which allowed its use at oxygen concentration below 2\%. In this system, as oxygen was consumed, it was replaced electrolytically. The electrolytic current was recorded automatically as a function of time of oxidation and the amount of oxygen to be replaced calculated from Faroday's Law of Electrolysis. The apparatus was a completely closed system independent of atmospheric pressure.

Another method of oxygen uptake study is through the use 
of oxygen electrodes. These electrodes have been used mainly in the fields of food analysis, biology, medicine, and biochemical engineering (Borkowski and Johnson, 1967; Flynn et al., 1967; Halback, 1977; Hospodka and Caslavsky, 1964; Johnson et al., 1964; Krebs and Haddad, 1972; Koch and Kruuv, 1972; Kok and Zajic, 1973; Kok and Zajic, 1975). Oxygen probes have also been used in the measurement of oxygen in silage (Rees, 1981), natural and wastewaters (Gilbert et al., 1982), for theoretical studies (Rutchi et al., 1981) and in food oxidation (Fioriti, 1977; Fischer and Deng, 1977; Mack et al., 1976; Pominski et a1., 1975; Quast and Karel, 1971; Quast and Kare1, 1972a; Riemer, 1977; Saguy et al., 1983; Spiehler, 1971; Teixeira-Neto, 1981).

The oxygen electrode is an amperometric system with a cathode consisting of $\mathrm{Au}, \mathrm{Pt}$, or $\mathrm{Ag}$ and an anode of $\mathrm{Pb}, \mathrm{Cd}$, $\mathrm{Ag} / \mathrm{Ag}_{2} \mathrm{O}$, or $\mathrm{Ag} / \mathrm{AgCl}$. Oxygen is reduced at the cathode via the following reaction: $\mathrm{O}_{2}+2 \mathrm{H}_{2} \mathrm{O}+4 \mathrm{e}^{-}=4 \mathrm{OH}^{-}$. A potential of 0.5 to 0.8 volt is applied to the electode and upon oxygen reduction, a current flows which is proportional to the concentration of oxygen in the cell.

Historically, oxygen electrodes can be divided into two types: membrane covered electrodes, and exposed cathode systems which include the dropping mercury electrode (DME) and platinum micro-electrodes. Examples of the use of the DME are Petering and Daniels (1938) and Sidwell et al. (1962). There are several disadvantages to the DME for use in food systems 
including the following: a) the electrode is restricted to dissolved oxygen measurement, b) the test medium must be conductive, c) the flow rate must be constant, and d) poisoning of the cathode can alter the calibraton by reducing the active electrode area.

The most significant advancement in the area of oxygen electrodes came when clark (1953) introduced an electrode in which the anode, cathode, and electrolyte were isolated from the test medium by a gas permeable-ion impermeable polymeric membrane. This electrode could be used for gas phase as well as dissolved $\mathrm{O}_{2}$ readings and was independent of the medium into which it was immersed. The concentration of oxygen in the cell is determined by the partial pressure of oxygen outside the cell and thusly dependent upon the premeability characteristics of the film. Watanabe and Leonard (1957) identified polyethylene, teflon, polyvinyl chloride, natural rubber, and silicone rubber as having sufficient permeability to be useful. of these, polyethylene had the best calibration stability and silicone rubber the worst. The performance characteristics of the membrane covered probes have been reviewed (Koch and Kruuv, 1972; Krebs and Haddad, 1972; Watanabe and Leonard, 1957). Among the difficulties encountered was the large background current (also called zero, offset, or nitrogen current). The four major sources of this current are: electrochemically active impurities in the electrolyte, electrical leakage, incorrect polarizing voltage, and back diffusion of oxygen 
(Krebs and Haddad, 1972). Koch and Kruuv (1972) address the zero current issue and describe ways of reducing this problem. Gases which reduce at the voltages used and thus cause current to flow will interfere with the $\mathrm{O}_{2}$ readings. For this reason, gases of $\mathrm{SO}_{2}, \mathrm{Cl}_{2}, \mathrm{Br}_{2}, \mathrm{I}_{2}$, and oxides of nitrogen should be avoided. Mercaptants and $\mathrm{H}_{2}$ S have a poisoning effect on the sensors but will not seriously affect liquid phase measurements (Anon., 1967).

Little work has been done using the electrodes at low oxygen pressures. The primary reason for this is that few oxidation studies at low oxygen pressures using $\mathrm{O}_{2}$ uptake as a variable have been performed. Other problems with the use of these probes at low pressures are: the pressure of the system may affect the physical properties of the membrane and thus change its permeability, or, the membrane housing itself may not be built to support vacuum thus allowing for membranedislodge and subsequent loss of electrolyte.

The most significant study of oxidation at low oxygen pressure using a polarographic probe is that of Teixeira-Neto (1981). In this study, oxygen uptake was monitored as a function of time in a model system containing $\beta$-carotene. Several probe-related difficulties were encountered including calibration stability and problems with soluble oxygen measurement (Teixeira-Neto, 1978).

Gas chromatographic analysis for oxygen and carbon dioxide determination has been described by various authors (Bishov and 
Henick, 1966; Fioriti et a1., 1975; Fioriti, 1977; Karel et a1., 1963; Ramstack et al., 1979; Saguy et al., 1983; Toumy et a 1., 1969; Widomski and Thompson, 1979). This is a relatively quick and simple method with applications to food oxidation study. The basic method involves sampling of the headspace gas through a port, septum, or other opening with subsequent injection into the GC column. A thermal conductivity detector measures the gases eluting from the column. The retention time of each peak and the peak area are used to identify and determine the quantity of each gas in the original sample. An obvious and important advantage of GC over the above mentioned methods is the ability to measure $\mathrm{CO}_{2}$. Carbon dioxide can be evolved in oxidizing foods and if not accounted for can lead to errors in volumetric measurements.

Another method useful for determination of gases inside containers involves the use of mass spectrometry. Much of the work in this area has been done with fermentations (Heinzle and Lafferty, 1980; Pungor et al., 1980; Reuss et al., 1975). One early paper (Woldring, 1966) described blood gas analysis using an MS. Although no work has yet been reported in food systems, mass spectrometry has potential in this area due to its ability to measure a variety of volatile compounds in both the gas and liquid phases. Also, Weaver et al (1976) described how immobilized enzymes can be used to convert non-volatile compounds of interest into MS-measurable volatile compounds.

The Quadrapole Mass Spectrometer (QMS) can be used as a 
programmable detector (Pungor et al., 1980) since it rapidly responds to a control voltage with the ion (or mass) peak measured proportional to the control voltage. In this way, one can select ion peaks to be monitored in a mass spectrum by the use of software. The determination is rapid (a few minutes), is reproducible, and shows good correlation with GC methods. The use of glucose oxidase (E.C. 1.1.3.4) to assay for dissolved oxygen is widely used (Capietti et al., 1977). However, the method has several drawbacks, the principal one being the high concentration of enzyme necessary to reach an appreciable rate of reaction. In order to get around this restriction, Capietti et al. (1977) described a method of oxygen determination using ascorbate oxidase (E.C. 1.10.3.3); an enzyme which stoichiometrically and specifically catalyzes the direct reduction of oxygen to water in the presence of Lascorbic acid. The amount of this enzyme needed is one-fortieth that of glucose oxidase and has better $\mathrm{pH}$ and temperature stability.

\subsection{Adsorbed/Entrapped Oxygen}

Dehydrated food packaged under vacuum or nitrogen atmosphere may contain entrapped or adsorbed gas which is almost impossible to remove completely (Haller and Holm, 1947); Tamsma et al., 1967). This gas may be held by physical entrapment, chemisorption, or to a lesser degree by physical adsorp- 
tion (Sidwell et al., 1962). The oxygen content of this gas could be responsible for initiating or promoting deteriorative reactions in oxygen sensitive components of dehydrated foods.

The composition of the entrapped gas varies somewhat with the storage time in an atmosphere of air (Haller and Holm, 1947). Their results showed that the entrapped gas contained 22 to $39 \%$ oxygen. A very recent study by Saguy and his coworkers (Saguy et al., 1983) reports a lower percent oxygen in a number of different foods. Their results show a range from 12.69 to $22.83 \% \mathrm{O}_{2}$.

The amount of oxygen held by dehyrated products maintained at different levels of moisture is still a matter of controversy. Some authors (Haller and Holm, 1947) reported that more oxygen was sorbed at lower moisture levels than at higher ones by dehydrated foods. Other authors (Sidwell et al., 1962) reported different oxygen-moisture sorption functionalities for different products. Sidwell and co-workers suggested that foods stable to oxidation would have more oxygen sorbed/entrapped at very low moisture levels (specifically, below the monolayer moisture value). Those products sensitive to oxidation would not show this trend due to consumption of the oxygen by sensitive components.

Methods of measuring the entrapped/adsorbed gas and determining its composition were reviewed by Coulter et al. (1951). Among the earlier methods of sorbed gas removal, that of Haller and Holm (1947) is significant as applied to dry milk. Their 
system involved evacuation of the sample for a desired period of time and to desired vacuum. This was followed by heating the sample to $70^{\circ} \mathrm{C}$ (or higher) for a period of about 6 hours with removal of the evolved gases every 30 minutes. This method was inconvenient due to the long determination time and large sample size $(200 \mathrm{~g})$. Also, the prolonged heating had the potential of causing deterioration (e.g. oxidation, nonenzymatic browning) in food.

Hetrick and Tracy (1948) used a manometric method for measurement of the sorbed gases from whole milk. This method entailed weighing of the whole milk powder (about $240 \mathrm{~g}$ ) into cans to a packing density of 0.5 grams per milliliter of container volume. The manometer was affixed to the can and a vacuum pulled. After approximately 2 minutes, the stopcock connecting the pump, can, and manometer was turned to connect the can and manometer only. As gas desorbed, the pressure in the manometer increased slowly to a constant value at equilibrium. The concentration of oxygen was found to be greater than 21 percent, thus agreeing with Haller and Holm. They postulated that the "extra" $\mathrm{O}_{2}$ corresponded to that dissolved in the liquid milk before spray drying. Problems with this method included large sample size needed, extremely long waiting times for equilibrium, and inability to measure the sorbed gas still on the powder at equilibrium conditions. Methods involving the dissolution of the powder in a liquid and measurement of the evolved gas include Muers and 
Anderson (1944), Rutgers (1947), Sidwell et al. (1962), Verhey and Lammers (1970), Teixeira-Neto (1978), and Saguy et al. (1983)

Muers and Anderson (1944) used a method involving the introduction of a suspension of the powder in propanol into boiling water with transference of the liberated gas to a graduated tube for measurement. A problem with this method was the difficulty encountered in keeping the propanol suspension free of air bubbles. The blanks were consequently found to be high and it became uncertain that the amount of gas in the suspension equalled the residual gas.

The method of Rutgers (1957) involved the dissolution of milk powder in oxygen-free water and measurement of the evolved gases in a calibrated tube at atmospheric pressure. Duplicate determinations showed a variation of $0.0-1.5 \mathrm{ml}$ per 100 grams powder, but this figure sometimes increased to $3-4 \mathrm{ml}$ per 100 grams powder. This was explained by variation in the vacuum pulled or in the blanks used. It should be noted that the oxygen present in the water (milk) phase was not measured but assumed negligible through a Henry's Law calculation. Also, the length of time of evacuation was noted as a very important variable with respect to amount of oxygen desorbed. Differences in amount of evolved gases of up to $20 \%$ were found between 15 minutes and 5 minutes of evacuation.

sidwell et al. (1962) used a polarographic method for the measurement of molecular oxygen in some dehydrated foods. 
This method consisted of introducing a 1 gram sample of pulverized food into a $1 \mathrm{oz}$. jar containing $30 \mathrm{ml}$ of deoxygenated $0.1 \mathrm{~N}$ potassium chloride solution. Measurements were made with a dropping mercury electrode and with a platinum cathode-silver anode probe covered by a polyethylene membrane. Values of 0.05 to $6.0 \mu \mathrm{M}$ oxygen per gram of sample were reported. The maximum reproducibility of their method was \pm $0.05 \mu \mathrm{M} \mathrm{O}_{2}$ per gram for duplicate samples. In this work, they also analyzed the effects of moisture content, processing, and headspace gas composition on the molecular oxygen content. The method of verhey and Lammers (1970) involved replacement of the flask's headspace gas with carbon dioxide. Ethanol and water were drawn into the flask to disintegrate the particles and liberate the residual gas. The gas was transferred to a burette in which the $\mathrm{CO}_{2}$ was removed with alkali and the remaining gas measured at $20^{\circ} \mathrm{C}$. The amount of oxygen in the gas was determined by pyrolgallol. In a sixfold analysis, a powder yielded residual gas volumes of 4.3 to $5.4 \mathrm{ml}$ gas/100 grams powder with a standard deviation of $0.08 \mathrm{ml} / 100 \mathrm{~g}$. With different samples, it was found tht the standard deviation increased with increasing residual gas volumes. For example, with gas volumes below $5 \mathrm{ml}$ gas/100 $\mathrm{g}$ the standard deviation was $0.11 \mathrm{ml} / 100 \mathrm{~g}$, whereas for gas volumes of $5-22 \mathrm{ml} / 100 \mathrm{~g}$, a standard deviation of $0.41 \mathrm{ml} / 100 \mathrm{~g}$ was found.

Teixeira-Neto (1978) described a method based upon the evacuation of the sample for 2-3 minutes, followed by addition 
of deaerated water to the solubilize the sample and thus release the entrapped gas. The headspace was compressed to 1 atmosphere and the oxygen concentration determined via an oxygen probe. The oxygen in the water was also measured. Values of entrapped $\mathrm{O}_{2}$ were reported for starch, Avicel, and milk powder. For these products, values were in the range of 0.26 $\mu \mathrm{M} \mathrm{O} /$ /gram (Avicel) to $1.25 \mu \mathrm{M} \mathrm{O} / \mathrm{g}$ (instant low-fat dry milk). Coefficients of variation were in the range 4.6-14.0\% Problems listed by Teixeira-Neto were: (1) leaks, (2) oxygen in the deaerated water, (3) clumping of the sample, (4) calibration of the probe, and (5) measurement of soluble oxygen. saguy et al. (1983) describe a modification of the Teixeira-Neto system involving the use of a gas chromatograph to measure the evolved gases after solubilizing the sample in deaerated water. Analysis of $\mathrm{CO}_{2}$ as well as $\mathrm{O}_{2}$ is reported. $\mathrm{O}_{2}$ in the water is determined by an oxygen probe, however, it should be noted that the $\mathrm{CO}_{2}$ in the water is not determined. Four commercial spray dried skim milk powders, one whole milk powder, apple base, banana base, carrot, honey, molasses, and orange base were tested. Potato powder and freeze-dried red beet powder were also analyzed. Values of entrapped/adsorbed gas for different spray dried milk powders ranged from $0.72-27.01 \mathrm{ml}$ gas/100 $\mathrm{g}$ with standard deviations of $0.12-0.61$ $\mathrm{ml} / 100 \mathrm{~g}$.

In the latter study, the authors also distinguish two general types of powders based upon residual gas found as a 
function of time of evacuation. Type I (e.g. milk powder, carrot base, beet powder) powders show a constant, nonzero amount of residual gas left after about 5 minutes of evacuation. Type II (e.g. instant potatoes) exhibit a markedly different behavior in that the time of evacuation determines the residual gas liberated by this procedure. The technological impact of type II powder is that a thorough evacuation of this type of food can potentially exclude all the retained gas, thus enhancing the stability.

2.3. Oxygen Uptake of Oxidizing Lipids as a Function of oxygen Partial Pressure

This part of the literature survey reviews work on oxidizing lipids in pure systems, model systems, and food.

\subsubsection{Pure Compounds}

Henderson and Young (1942) conducted an investigation of the effect of very high oxygen partial pressurs on purified oleic acid at high temperature. They used oxygen partial pressures of $0.21,0.5,0.75$, and $1.0 \mathrm{~atm}$. The temperature was $80^{\circ} \mathrm{C}$. Under these somewhat severe conditions, they found that while the induction period was unaffected by different oxygen concentrations, the rate was a function of $\mathrm{O}_{2}$. Specifically, they found the rate of oxidation at $0.21 \mathrm{~atm}$. to be about half that at $1 \mathrm{~atm}$. Based on the kinetic data, they derived the equation, 


$$
-d\left(O_{2}\right) / d t=c_{1}+c_{2}(\text { peroxide })\left(O_{2}\right)^{1 / 2}
$$

where:

$$
\begin{aligned}
\left(\mathrm{O}_{2}\right) & =\text { concentration of oxygen } \\
t & =\text { time } \\
c_{1} \& c_{2} & =\text { empirical constants }
\end{aligned}
$$

A series of studies performed at the British Rubber Producers Association during the period 1940-1953 laid the basic groundwork for subsequent studies of the oxidation of unsaturated oils. Bolland (1949), Bateman (1954), and Lundberg (1954) have written reviews of their work during this period. These workers set forth the chain reaction mechanism of oxidizing olefins and this work, applied to oils serves as the basic theory of lipid oxidation. Karel (1960) and Labuza (1971) present reviews of lipid oxidation kinetics and mechanism. oxygen partial pressure functionality on ethyl esters of unsaturated fatty acids is treated by the above-mentioned workers in several papers (Batemen, 1954; Bolland, 1946; Bolland and Gee, 1946; Bolland, 1949). With the reaction vessels shaken to avoid oxygen diffusion limitations, the following conclusions were arrived at:

(1) The following equation represented the oxygen functionality: 


$$
-d\left(\mathrm{O}_{2}\right) / d t=k(\mathrm{RH})(\mathrm{ROOH}) f\left(\mathrm{PO}_{2}\right)
$$

where:

$$
\begin{aligned}
\mathrm{f}\left(\mathrm{PO}_{2}\right) & =\mathrm{PO}_{2} /\left(\mathrm{n}+\mathrm{PO}_{2}\right) \\
(\mathrm{RH}) & =\text { concentration of unoxidized fatty acid } \\
(\mathrm{ROOH}) & =\text { concentration of hydroperoxide } \\
\mathrm{PO}_{2} & =\text { partial pressure of oxygen }(\mathrm{mm} \mathrm{Hg}) \\
\mathrm{n}, \mathrm{k} & =\text { constants }
\end{aligned}
$$

(2) Little effect of $\mathrm{PO}_{2}$ on rate of oxidation at $45^{\circ} \mathrm{C}$ was found until $\mathrm{PO}_{2}$ of less than $50 \mathrm{~mm} \mathrm{Hg}$ were used.

(3) The dependence of oxygen absorption rates on the partial pressure of oxygen increased with increasing temperatures.

(4) The more reactive the compound studied, the more dependent its rate of oxidation was on oxygen partial pressure.

In contrast to the work of Bolland, where oxygen diffusional limitations were considered negligible, Karel (1960) undertook an extensive study of the role of oxygen partial pressure on linoleic acid oxidation under conditions of limited surface area. He followed oxygen absorption in samples of $2 \mathrm{ml}$ volume and ranging from $0.515 \mathrm{~cm}^{2}$ to $12.6 \mathrm{~cm}^{2}$ surface area. Oxygen partial pressures were varied over the range $5 \mathrm{~mm} \mathrm{Hg}$ to $735 \mathrm{~mm} \mathrm{Hg}$. The following conclusions were derived from the data: 
(1) After an initial lag period, the amount of oxygen absorbed increased linearly with time. This linear relationship could be explained by the rate of oxygen diffusion being the limiting factor.

(2) The rate of oxidation vs. partial pressure of oxygen data made up a family of curves described by the following equation:

$$
\mathrm{R}_{0}=1 /\left(\mathrm{k}_{1}+\mathrm{k}_{2} / \overline{\mathrm{PO}}_{2}\right)
$$

where:

$$
\begin{aligned}
\mathrm{R}_{0} & =\text { steady rate of oxygen absorption }(\mathrm{cc} / \mathrm{hr}) \\
\overrightarrow{\mathrm{PO}}_{2} & =\text { average partial pressure of } \mathrm{O}_{2}(\mathrm{~mm} \mathrm{Hg}) \\
\mathrm{k}_{1} & =\text { constant }(\mathrm{hr} / \mathrm{cc}) \\
\mathrm{k}_{2} & =\text { constant }(\mathrm{hr})(\mathrm{mm} \mathrm{Hg}) / \mathrm{cc}
\end{aligned}
$$

This equation was obtained by plotting $1 / \mathrm{R}_{\mathrm{O}} \mathrm{vs} \cdot 1 / \overline{\mathrm{PO}}_{2}$ and evaluating the constants from the slope and $y$-intercept of the resulting straight line.

(3) The dependence of the rates of oxidation on the oxygen pressure was most pronounced at the lowest surface area.

(4) Comparing the rates of oxidation at different temperatures, it was found that oxygen pressure has less 
effect on the relative rate at $37^{\circ} \mathrm{C}$ than at $57^{\circ} \mathrm{C}$. This was also found in the studies in well-agitated vessesls (Bateman, 1954; Bolland, 1949).

(5) Overall, a much greater effect of oxygen pressure on rate was found in this study than in Bolland and co-workers' studies. Due to the oxygen diffusion limitations, these results are in accord with theoretical expectations.

Emulsions of fatty acids and esters were studied by Marcuse and Fredriksson $(1968,1969)$ at low oxygen partial pressure. They were able to show that the dependence of the rate of fat oxidation on oxygen pressure in emulsions was in part attributable to conditions inherent in the chain reacting system and in part due to the limiting effect of diffusion of oxygen. The results of Bolland and Karel were confirmed with respect to various factors: (a) greater substrate reactivity meant greater $\mathrm{PO}_{2}$ dependence, (b) increasing temperature meant increasing $\mathrm{PO}_{2}$ dependence, (c) lowering the $\mathrm{pH}$ from 6 to 5 decreased the rate of reaction and also increased the oxygen dependence. It was also found that the degree of rate limitation due to slow diffusion of oxygen increased with decreasing oxygen concentration. Both the expressions for rate $=f\left(\mathrm{PO}_{2}\right)$ of Bolland and Karel imply a straight line when 1/rate vs. $1 / \mathrm{PO}_{2}$ is plotted. Marcuse and Fredriksson found that their data plotted in this manner tended to deviate from a straight 
line. Only during an early period (e.g. up to a rate of 40 $\mathrm{mm}^{3} \mathrm{O}_{2} / \mathrm{hr}$ ) could a straight line be drawn. Above this, they argued, the diffusional limitation causes deviation from a straight line.

In terms of antioxidant effectiveness on emulsions of linoleic acid at reduced $\mathrm{PO}_{2}$, Marcuse and Fredriksson (1969) found that phenolic inhibitors ( $\alpha$-tocopherol, BHA, PG) formed an induction period which was, in general, not dependent on oxygen pressure. oxidative rate retardation caused by amino acids (glycine, alanine, histidine, tryptophan) was stronger at low oxygen pressure than in air. A synergistic effect was found when the two types of inhibitors were added in combination, and this effect considerably enhanced at low oxygen pressure.

\subsubsection{Model systems}

Model systems simulating foods can be used to study reactions of components of interest without worrying about other food constituents complicating the system. By virtue of this fact, however, caution must be used when extrapolating from model systems to real foods.

Karel (1960) investigated the effect of partial pressure of oxygen on the oxidation of linoleic acid dispersed on powdered cellulose at three oxygen pressures: $30 \mathrm{~mm} \mathrm{Hg}, 130 \mathrm{~mm}$ $\mathrm{Hg}$, and $730 \mathrm{~mm} \mathrm{Hg}$. He found that the oxidation rates at the 
three different pressures were almost identical and thus concluded that under conditions in which unsaturated fatty acids are dispersed on porous materials, oxygen diffusion is almost completely unhindered. Karel's results were similar to those in rapidly shaken vessels (Bateman, 1954; Bolland, 1946). Marcuse (1967) studied the effect of low oxygen pressure on freeze-dried model systems consisting of linoleic acid as substrate with cellulose, starch, gelatin, albumin, and casein as supporting materials. The concentrations used were 1:1 lipid to supporting material except for gelatin which was $0.2: 1$. In accordance with Karel's conclusions (see above paragraph), oxidation of linoleic acid on the powdered support was much less dependent on $\mathrm{PO}_{2}$ than linoleic acid in bulk. Marcuse also found that the rate decreasing effect of lowered $\mathrm{PO}_{2}$ is influenced by the type of supporting material. The oxidation kinetics of the oil dispersed on starch and casein were more a function of oxygen pressure than the oil on cellulose. The oxygen functionality of freeze-dried model systems containing various metal ions was also investigated by Marcuse (Marcuse, 1967). When the oxygen content was lowered to $0.58 \mathrm{O}_{2}$, the effect of $\mathrm{Cu} 2+$ became strongly antioxidant on cellulose and starch while on casein it was prooxidative. On cellulose, $\mathrm{m}^{2+}$ had an antioxidative effect while no effect was found with $\mathrm{Co}^{2+}$ and $\mathrm{Fe}^{2+}$.

\subsubsection{Food Systems}


The area of lipid oxidation in dehydrated foods at low $\mathrm{PO}_{2}$ is a poorly studied area from the point of view of kinetics. As seen in the previous section of this review, dehydrated systems tend to have large surface areas, thus necessitating extremely low oxygen concentrations to significantly alter the rate. As previously discussed, studies at such low $\mathrm{PO}_{2}$ require special equipment to perform.

As reviewed by Labuza (1971), the major work done on oxygen level on stability of dried milk was done with foam and spray dried whole milk (Tamsna et al., 1961; Tamsma and Pallansch, 1964; Aceto et al., 1965; Aceto et al., 1966; Tamsma et al., 1967; Kontson et al., 1969; Cornell et al., 1971; Parks et al., 1969). Kinetic experiments were not performed, and stability was judged organoleptically in these experiments. For foam-dried whole milk, levels of oxygen of less than 18 were needed to give sufficient shelf life at room temperature. In air, the first faint odor was noticed in about 1 week. At $1 \% \mathrm{O}_{2}$, storage life increased to 3 weeks and at $0.18 \mathrm{O}_{2}$ to 4-5 months. Spray dried whole milk has a slightly longer shelf 1 ife due perhaps to production of antioxidants during drying at higher temperatures.

A series of studies at the U.S. Army Natick Research and Development Laboratories of oxygen level effects on dehydrated beef products came up with some specific recommendations for proper storage (Toumy et al., 1968a; Toumy et al., 1968b; Toumy et al., 1969; Toumy et al., 1970; Bishov et al., 1971). The 
following conclusions could be drawn from these studies (Labuza, 1971):

(1) Dehydrated raw beef patties had a storage life of 6 months at vacuums less than $20^{\prime \prime} \mathrm{Hg}$ while in air, the storage life was about 1 month.

(2) Cooked, dehydrated beef stew had a storage life of more than 24 weeks at 30 "Hg vacuum but only 4 weeks in air. The predicted shape of the curve for rate of oxidation vs. $\mathrm{PO}_{2}$ ( $1 /$ Rate vs. $1 / \mathrm{PO}_{2}$ gives a straight line) was observed in this system. Chicken stew became rancid in just about 2 weeks in air and at low oxygen.

(3) Oxidation rates were initially rapid even at $2 \% \mathrm{O}_{2}$ for chicken, beef, and pork with rancidity detected at the 5 th, 2nd, and lst month, respectively. The stability was increased to more than one year by using a $5 \% \mathrm{H}_{2}$ atmosphere with a palladium catalyst to reduce the oxygen level to "zero".

Marcuse (1967) studied the oxidation of lipids and $\beta$-carotene in freeze dried carrot slices at low oxygen pressure. In summary, it was found that the relative rate of oxidation at Low $\mathrm{PO}_{2}$ (relative to $\mathrm{PO}_{2}=.21 \mathrm{~atm}$ ) was low compared to model systems. He suggested that the differences arose due to slow 
diffusion of oxygen in the carrot slice. He therefore made the suggestion that freeze-dried carrrot slices can be effectively protected against oxidaton by storage at a much higher pressure than required for protection of a freeze-dried powdered system. Quast and Karel (1971) studied the effects of oxygen diffusion on the oxidation of potato chips, fish meal, foam-dried whole milk, and a commercial snack food ("Bugles"). It was found that for potato chips, dried milk, and Bugles, oxygen diffusion was not a rate limiting factor of oxidation. On the other hand, fish meal oxidation showed a linear relationship between rate of oxidation and $\mathrm{PO}_{2}$, thus showing a diffusional limitation.

The work with potato chips was continued by Quast and Karel (1972a) as they investigated the effects of light, temperature, equilibrium relative humidity, extent of oxidation, and oxygen concentration on the rate of oxygen uptake. The oxygen concentrations studied were $0.0055,0.035,0.072,0.122$, and 0.21 atm of partial pressure. It was found that in all cases, the rate was a very strong function of oxygen concentration when the concentration was low. A mathematical model was developed (Quast and Karel, 1972b) for the rate of oxidation of potato chips as a function of the extent of oxidation, equilibrium relative humidity, and oxygen partial pressure. The oxygen dependence was modeled with the equation used by Karel (1960) viz: 


$$
\text { Rate }=\mathrm{PO}_{2} /\left(\mathrm{P}_{1}+\mathrm{P}_{2}\left(\mathrm{PO}_{2}\right)\right]
$$

where:

$\mathrm{P}_{1}$ and $\mathrm{P}_{2}$ are constants.

Excellent agreement with the equation was found when $\mathrm{P}_{1} / \mathrm{PO}_{2}$ was plotted versus 1/Rate. The average mean square error was 0.010 . This study by Quast and Karel is the most thorough work performed to this time on the environmental factors affecting lipid oxidation in a food. 
3. MATERIALS AND METHODS

3.1. Adsorbed/Entrapped Oxygen Measurement

3.1.1. Principle

This apparatus worked on the principle of solubilization of the sample in deaerated water, liberation of gases adsorbed or entrapped in the sample and compression of the evolved gases to atmospheric pressure in a calibrated tube. Oxygen determinations in the gas and in the water were made using oxygen probes.

3.1.2. Apparatus

A schematic diagram of the system is shown in Figure 1 . The system consisted of the sample flask (1) (with a primary neck and sidearm) containing the sample and a stir bar immersed in a constant temperature bath maintained at $25^{\circ} \mathrm{C}$ by a temperature controller (10). The flask was connected via stopcock "2" to a heat exchanger (3) which in turn was connected to the deaerated water flask (4). The sample flask was also connected via the three-way stopcock (14) to the measuring part of the system. This part of the system consisted of a graduated $2 \mathrm{ml}$ Pyrex pipette (5) with an oxygen probe (7) connected to the top. The probe was plugged into the oxygen analyzer (11) which 
Figure 1

Apparatus for Determination of Adsorbed/Entrapped Oxygen

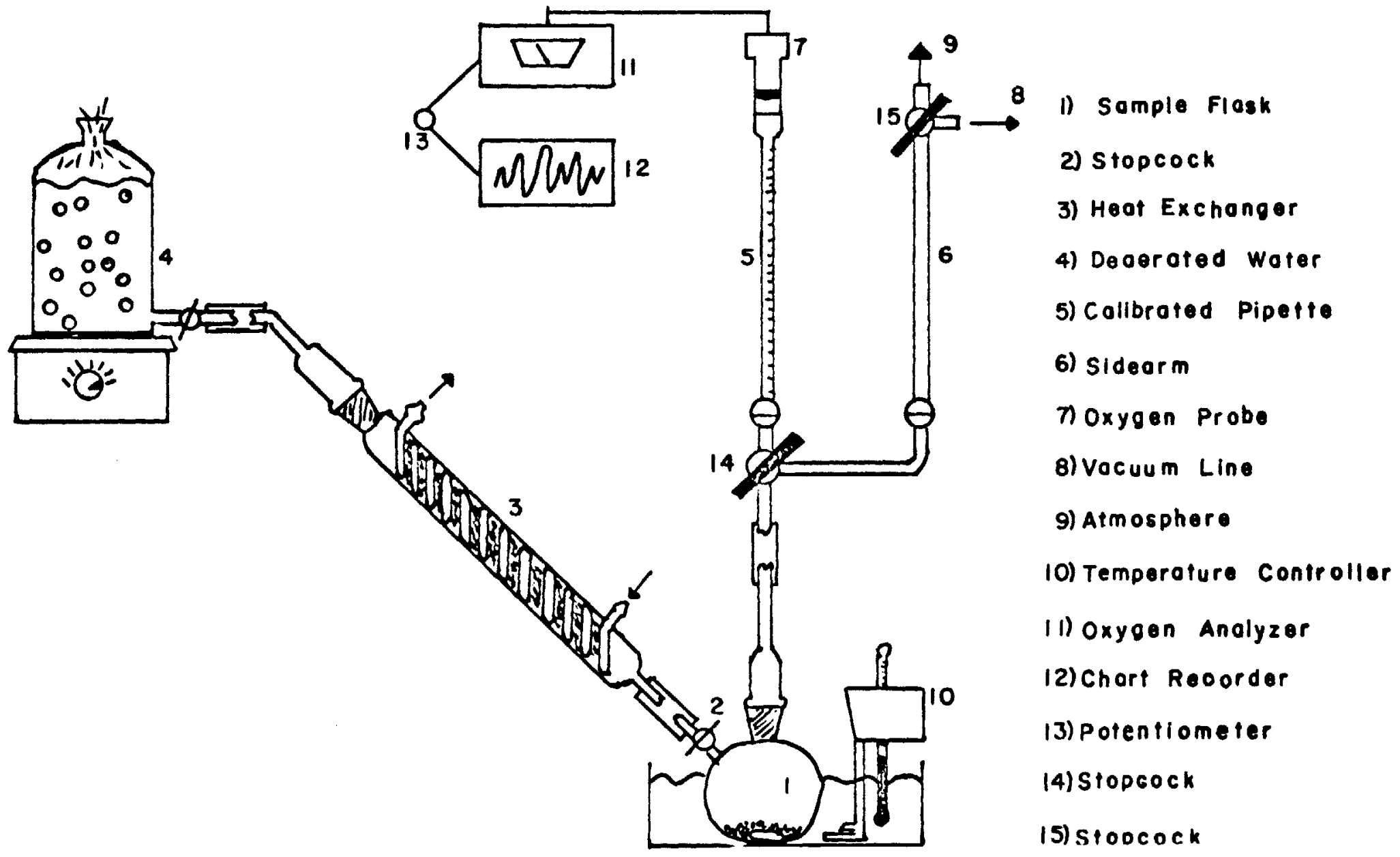

$\stackrel{w}{\infty}$ 
was in turn connected to a strip chart recorder (12) via a potentiometer (13). The stopcock (14) also serviced the other arm of the system (6) which could be connected to a vacuum pump (8) or open to the atmosphere (9) via a three way stopcock (15). The temperature controller (10) was a model Thermonix 1441 (Braun Instruments). The oxygen analyzer and probe ( 7 and 11) was the model 777 (Beckman Instruments, Inc., Fullerton, CA). The probe used in the dissolved oxygen determination (not shown in the figure) was an Altex Model 0260 (Beckman Instruments, Fullerton, CA). The strip chart recorder was an Omniscribe B-5000 (Houston Instruments, Austin, TX). The potentiometer was a $250 \mathrm{ohm}$ unit type $A B$ made in the USA.

\subsubsection{Procedure}

The procedure for determination of the oxygen adsorbed/entrapped within the powder required seven steps. These were: a) deaeration of the water, b) calibration of the probes, c) evacuation of the system, d) solubilization of the sample, e) compression of the headspace gas, f) measurement of the gaseous oxygen and, g) measurement of the dissolved oxygen.

a. Deaeration of the Water. This was accomplished by boiling deionized water for a minimum of thirty minutes before allowing the water to flow into the flask. Blanks prepared with this deaerated water and no powder showed a neglible amount of oxygen in this water. 
b. Calibration of the Probes. For gaseous oxygen readings at the higher $\mathrm{O}_{2}$ pressures $\left(5\right.$ and $\left.10 \% \mathrm{O}_{2}\right)$, the switch on the $\mathrm{O}_{2}$ analyzer (11) was set to the $25 \%$ range. A vacuum was then pulled on the system using an oil vacuum pump through line 8 and the strip chart pen adjusted to 0 using the "zero control" knob on the $\mathrm{O}_{2}$ analyzer. The system was then opened to the atmosphere (9) and using the "calibrate control" knob on the analyzer, the pen was moved to full scale on the strip chart, corresponding to $21 \% \mathrm{O}_{2}$. For gaseous oxygen readings of less than $5 \frac{\mathrm{O}_{2}}{2}$, the system was connected to a manometer and the scale on the meter-amplifier unit set to $5 \%$. The vacuum pump was turned on and after stabilization of the reading (2-3 minutes), the pen on the chart was adjusted to zero. The system was very slowly opened to the atmosphere, thus letting in small amounts of air. The manometer pressure corresponding to this small pressure in the system was read, and the recorder pen adjusted to this pressure by using the "calibrate" control knob. Under these conditions, the full scale on the strip chart corresponded to $5 \% \mathrm{O}_{2}$.

Replacement of the teflon membrane on the probe was done periodically according to the manufacturer's instructions and the linearity of the probe response to varying pressures of oxygen checked each time the membrane and electrolyte were replaced.

The probe used for dissolved oxygen measurements was calibrated by immersing it in water deaerated as described in 
section $3.1 .3 . \mathrm{a}$. at $25^{\circ} \mathrm{C}$. The pen on the strip chart was adjusted to zero. The water was then shaken vigorously in air for fifteen minutes and the probe immersed in this water to get the full scale readings. For both probes, the procedures were repeated several times until reproducible readings were obtained. For calibration and readings of dissolved oxygen, the liquid to be analyzed was kept moving past the probe membrane by constant stirring using a magnetic stirrer.

\section{c. Evacuation of the System. Vacuum was pulled on the} entire system via line 8 with stopcock 15 connected to 8 and 6 only. Stopcock 14 was open to all three positions $(1,5$, and 6$)$ and stopcock 2 was open to the heat exchanger (3). This evacuation continued for 10 minutes.

d. Solubilization of the Sample. After evacuation, stopcock 14 was opened to flask 1 and tube 5 only (closed to 6). Water from flask 4 was slowly let into 1 through the heat exchanger (3) while the magnetic stirrer continously stirred the flask contents. As the water rose in the flask, the gas evolved rose into 5 .

e. Compression of the Headspace Gas. The water was allowed to rise until it entered the calibrated tube (5). Once the meniscus was above stopcock 14, this stopcock was turned to 1 and 6 only (closed to 5) and the water allowed to enter 6 up 
to a level roughly equal to the meniscus in 5 . Stopcock 14 was then turned to 5 and 6 only (closed to 1 ) and stopcock 15 opened to the atmosphere. When the water levels were equal, the gas in 5 was at the same total pressure as the gas in 6 , i.e. atmosphere pressure.

f. Measurement of the Gaseous Oxygen. The recorder pen was given time to stabilize and upon stabilization, the volume in tube 5 recorded. Temperature was measured with a mercury thermometer and equal to ambient temperature. The total pressure was atmospheric pressure (usually around $760 \mathrm{~mm} \mathrm{Hg}$ ). The ideal gas equation gave the number of $\mu$ moles of oxygen present in the gas.

g. Measurement of Dissolved Oxygen. Once stopcock 14 was closed off to 1 , the sample flask could be removed and the dissolved oxygen in the flask analyzed. This was done by inserting the other oxygen probe slowly to the bottom part of the flask. The magnetic stirrer allowed for enough fluid to move past the probe tip to prevent oxygen limitation effects in the vicinity of the membrane (the probe consumes the oxygen it analyzes). The oxygen dissolved could be read directly on the oxygen analyzer in ppm or $8 \mathrm{O}_{2}$.

Adding together the values of gaseous and dissolved oxygen, the amount of oxygen held by the powdered food can be calculated. 
3.2. Headspace Gas Measurement

The oxygen present in the flask headpsace was the most important measurement made for the oxygen uptake studies. A sample flask which had been incubated for a period of time was connected via vacuum tubing to stopcock 14 which was open to the 3-way position. Vacuum was pulled on the system until the previously calibrated probe (7) showed a steady reading at 0 . Stopcock 14 was then turned in the direction of 1 and 5 only (closed to 6) and the hose clamp closing off the sample flask from the system removed. The headspace gas in the sample now filled the small volume of tube 5 and the partial pressure measured by the oxygen probe. Since the total volume, temperature, and pressure were known, the ideal gas equation was used to derive the number of moles of $\mathrm{O}_{2}$ in the headspace.

\subsection{Diene Conjugaton Analysis}

This method involved the extraction of the lipid-soluble components of the sample into methanol with the subsequent determination of U.V. absorbance at $233 \mathrm{~nm}$ in a Hitachi-Perkin Elmer 200 spectrophotometer. The extinction coefficient of conjugated dienes is 29000 * compared to $6026 *$ * for nonconjugated methyl linoleate. The assumption on which this test is based is that the major oxidation products are conjugated hydroperoxides. Schemtically: 


\author{
$0.5 \mathrm{~g}$ model system $+50 \mathrm{ml}$ methanol \\ $+\operatorname{Mix} 15-20 \mathrm{~min}$ \\ Centrifuge o $15000 \mathrm{rpm} / 10 \mathrm{~min}$ \\ $\downarrow$ \\ Dilutions as needed \\ $\downarrow$ \\ Read absorbance at $233 \mathrm{~nm}$
}

*Privett and Blank, 1962

**CRC Atlas of Spectral Data and Physical Constants, Vol. III.

3.4. Sorption Isotherm Preparation

The sorption isotherm was prepared by weighing one to two gram samples of the dried milk (prepared as in section 3.6 .2 but without lipid) into $50 \mathrm{ml}$ beakers of diameter $40 \mathrm{~mm}$. The beakers were placed in dessicators containing saturated salt solutions with water activities ranging from $0.55(\mathrm{NaOH})$ to .75 $(\mathrm{NaCl})$ at $37^{\circ} \mathrm{C}$. These samples were repeatedly weighed until they reached equilibrium, at which time the moisture content on a dry basis was calculated.

3.5. Determination of Flask and Sample Volumes

The flask volume was determined by weighing the flask and magnetic stir bar, then filling the flask with water at a 
measured temperature. The difference in these two weights divided by the density of water at that temperature is the flask volume.

The specific volume of the powder was determined by weighing a certain amount of the powder into a $100 \mathrm{ml}$ volumetric flask. The flask was then filled with water at a known temperature and this total weight recorded. This weight divided by the density of water is the volume of water. The specific volume is then $100 \mathrm{ml}$ minus the volume of water divided by the weight of sample. For example, if the weight of powder $=10 \mathrm{~g}$, volume of water used $=89 \mathrm{ml}$, the specific volume $=(100-89) / 10=1.1 \mathrm{ml} / \mathrm{gram}$.

3.6. Preparation of Samples

3.6.1. Model System

The model system consisted of Avicel microcyrstalline cellulose pH 101 (FMC Corp., Philadelphia, PA) and methyl Iinoleate (NuChek Prep, Elysian, MN). The preparation procedure was as follows:

Avicel + methyl linoleate + methanol

$\downarrow \quad$ Mix to uniform gel

( in the dark)

Dessicator - 12 hours (or until methanol evaporated) 


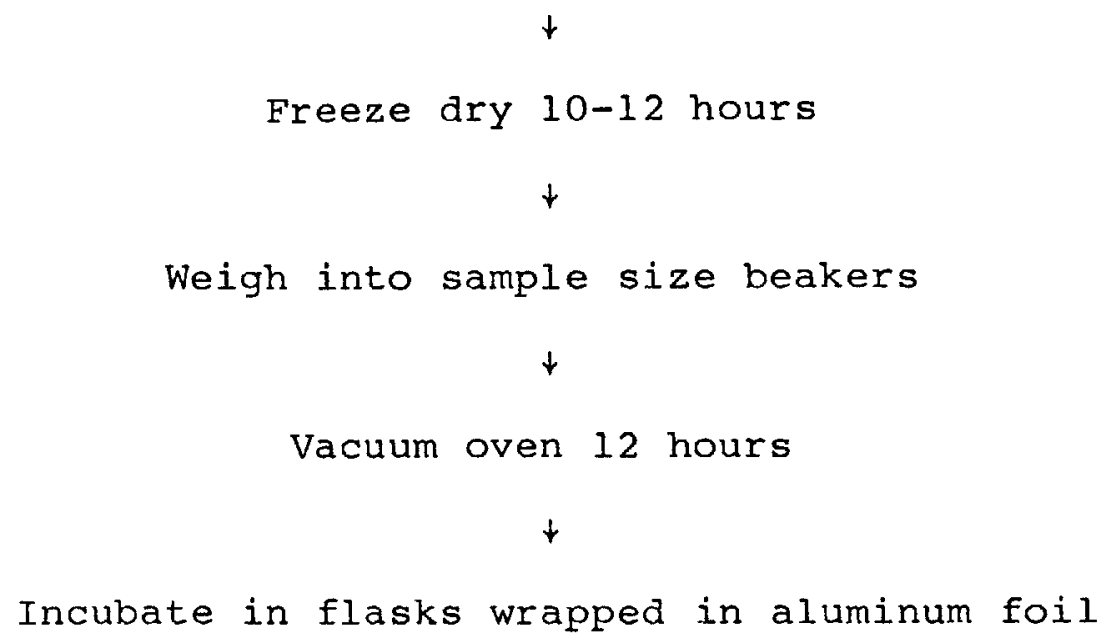

3.6.2. Milk-Lipid System

This system consisted of nonfat dry milk (Carnation Co., Los Angeles, CA) and methyl linoleate (NuChek Prep, Elysian, MN) prepared as follows:

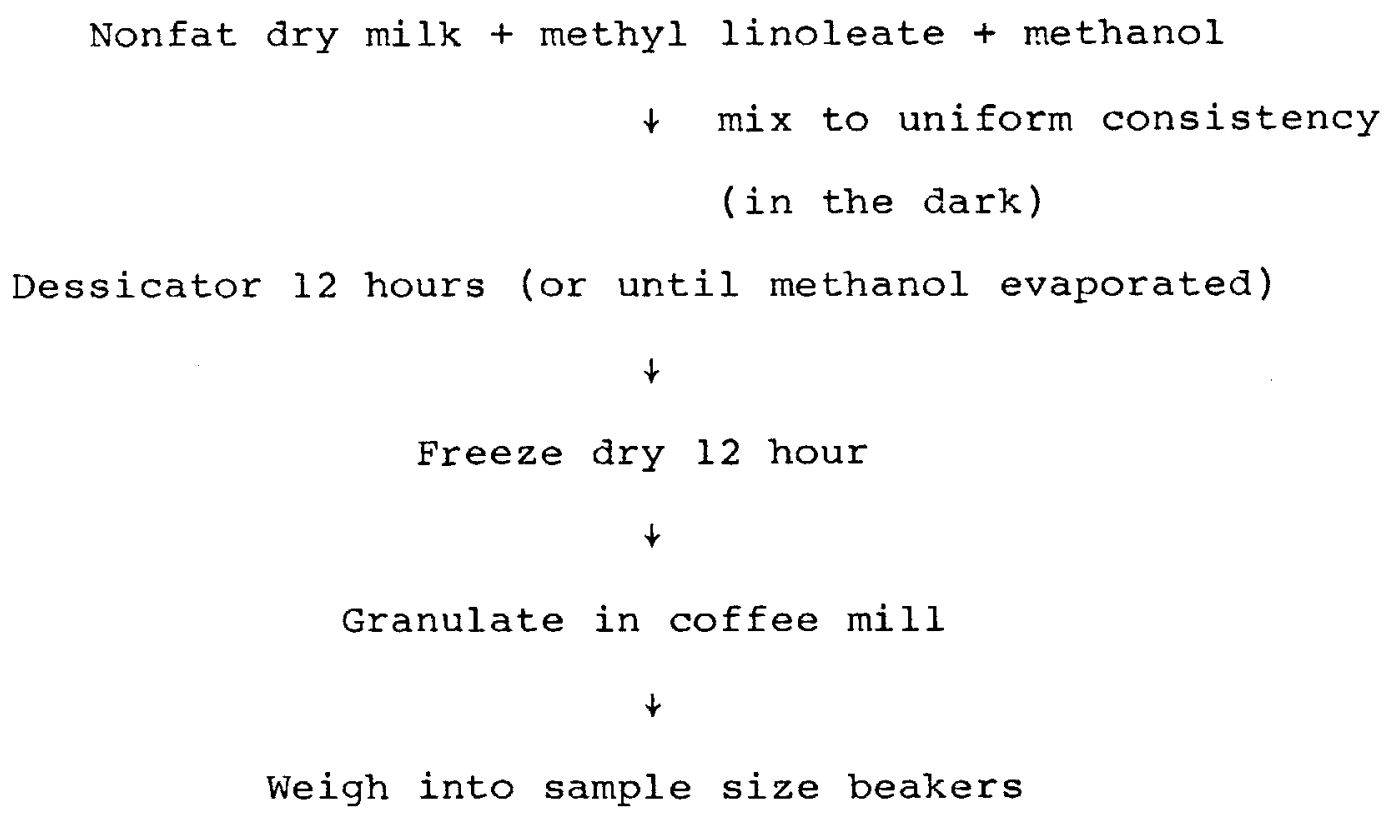




\author{
Vacuum oven 12 hours \\ Incubate in flasks wrapped in aluminum foil
}

3.7. Filling the Flasks with Various $\mathrm{O}_{2} / \mathrm{N}_{2}$ Mixtures

The sample flasks to be incubated were initially filled with the desired $\mathrm{O}_{2} / \mathrm{N}_{2}$ concentrations in the following manner. A manifold was constructed with ports to 10 sample flasks, a port leading to a manometer and a 3-way stopcock with one arm connected to the manifold, one arm to a vacuum pump, and the other arm to the compressed tanks of $\mathrm{O}_{2} / \mathrm{N}_{2}$ mixtures. These mixes were bought pre-mixed from Matheson Gas Co., Gloucester, MA. When the filling operation was to commence, a vacuum was pulled on the flasks and manometer. After 3-4 minutes, the 3-way stopcock was turned in the direction of the gas mixture and sample flasks only (closed to vacuum). The gas mixture was let in slowly until the manometer showed that the pressure in the flasks was equivalent to that of the atmosphere. This procedure was repeated several times to exclude any of the original gas. After the last cycle, the flasks were closed by pinching the vacuum tubing connecting the flasks to the manifold with a hose clamp. The flasks could then be incubated for the kinetic studies.

\title{
3.8. Problems Encountered
}




\subsubsection{Leakages}

The system leaked in many places, but the 3-way stopcocks were the main culprits. These had to be re-lubricated with vacuum grease every 2-3 days to avoid leaks. A high frequency vacuum tester (Electro Technic Products, Chicago, IL) was useful for detecting pinhole leaks and other hard to find leaks.

\subsubsection{Calibration of the Probe}

The probe mounted on the system (\#7, Fig. 1) sometimes took a long time to calibrate and would give erratic readings. The cause of these problems was not always apparent, but as the teflon membrane increased in age and usage, the calibration and stability problems always got worse.

\subsubsection{Measurement of Dissolved Oxygen}

After insertion of the dissolved oxygen probe into the milk-lipid aqueous phase of the sample, the probe readings sometimes decreased below the zero value (as determined by calibration to 0 with only deaerated water). The lipid alone was not responsible since putting a quantity of lipid in deaerated water up to 10 times the concentration of that in the regular milk-lipid samples did not depress the readings. Similarly, lactose dissolved in deaerated water at the con- 
centration in the regular samples did not depress the readings either. The milk alone (without lipid) did depress the readings. Casein would not dissolve in the water to adequate concentration, but due to the fact that the other major components were not at fault, the protein is implicated. The protein may have been interacting with the teflon membrane and decreasing its oxygen permeability directly, or it may have been adsorbing onto the membrane in a film and thus decreasing the effective permeability. In order to get the membrane probe to respond as before, the membrane had to be washed thoroughly with deionized water.

3.8.4. Glass Compatibility and the Sorbed Oxygen Apparatus

In order to build a probe (7) into the system for sorbed $\mathrm{O}_{2}$ measurement, a holder for the probe tip had to be joined to the calibrated pipette (5). It took a long time to find a pipette which was compatible with the glass holder. Even though the pipettes had the name Pyrex and Kimax (both borosillicate glass), unless the compatibility was just right, the slightest stress would cause the probe to break off the pipette at the junction point. 


\section{RESULTS AND DISCUSSION}

4.1. Oxygen Adsorbed/Entrapped in Nonfat Dry Milk

In order to determine the reproducibility of the method for determination of sorbed oxygen using the apparatus described in section 3.1, samples of nonfat dry milk, prepared as in section 3.6.2 without added lipid, were evaluated.

Table 1 shows that the average amount of oxygen held entrapped by the powder was $3.61 \mu$ moles $\mathrm{O}_{2} /$ gram of powder. The coefficient of variation was $20 \%$. Sample calculations are included in Appendix $A$ and the coefficient of determination calculations are done in Table 1 .

The values found for the adsorbed oxygen were greater than those reported by Teixeira-Neto $(1978)\left(.74-1.25 \mu\right.$ moles $\left.o_{2} / g\right)$

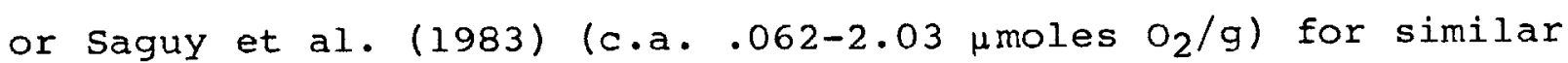
milks. The difference is due most likely to the difference in moisture content of the samples. As shown by sidwell et al. (1962), the sorbed oxygen content of powdered foods increases dramatically below the monolayer value. Both Teixeira-Neto (1978) and Saguy et al. (1983) used milk powder at the moisture content received from the supplier. 
Table 1

Values of $\mathrm{O}_{2}$ Adsorbed/Entrapped in Nonfat Dry Milk

(4 gram samples)

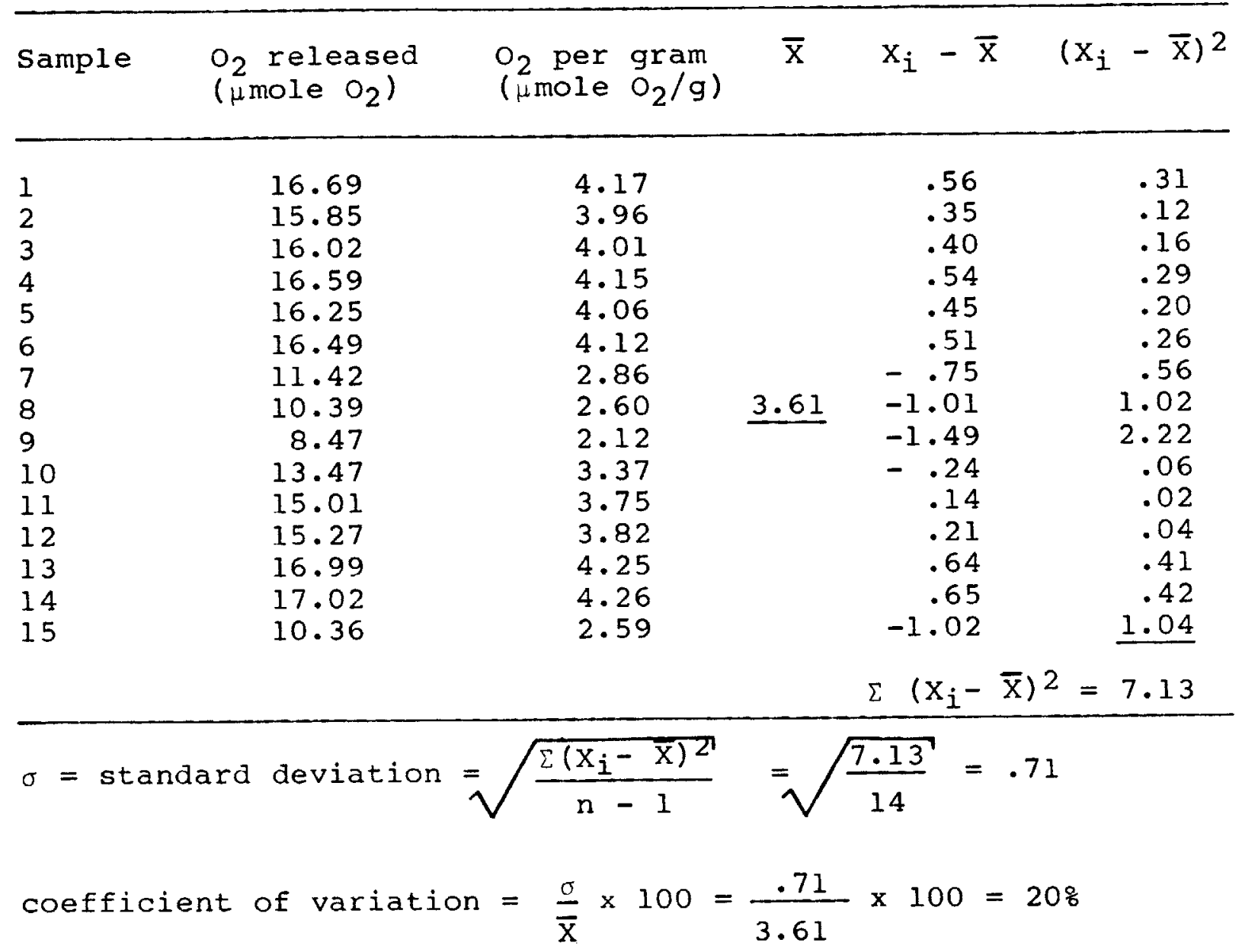


The initial moisture content of the milk used in the present study (before treatment in any way) was $3.5 \mathrm{~g} \mathrm{H}_{2} \mathrm{O} / 100 \mathrm{~g}$ powder. the samples used by Teixeira-Neto (1978) and Saguy et al. (1983) probably had about the same amount. Appendix C shows that the monolayer value in the nonfat dry milk used in these experiments was about $2.1 \mathrm{~g} \mathrm{H}_{2} \mathrm{O} / 100 \mathrm{~g}$. It can be assumed that the procedures for sample preparation used here reduced the moisture content well below the monolayer value. Also, the prepared milk powder was kept for about two weeks (prior to analysis) in a dessicator over $\mathrm{CaSO}_{4}$, in air, and at about $4^{\circ} \mathrm{C}$. The percent oxygen in the powder was about $21 \%$, this being lower than the slight $\mathrm{O}_{2}$ enrichment $(20.9-22.8 \%)$ reported by Saguy et al. (1983) or the $29-30 \% \mathrm{O}_{2}$ reported by Verhey and Lammers (1970). This is reasonable considering that the gases originally present in the milk were probably removed during sample preparation.

It should also be noted that the analysis yielded no detectable dissolved oxygen in the water. This is consistent with the findings of saguy et al. (1983). They found that prolonged evacuation of the sample (resulting in a partial drying of the powder) seemed to release the gases to the headspace more quickly than the more humid samples. They found this in all of their experiments and for all the food powders studied.

\subsection{Model System Studies}


Experiments were conducted in a model system consisting of methyl linoleate dispersed on Avicel microcrystalline cellulose and prepared as described in section 3.6.1. Samples were incubated in the dark at $37^{\circ} \mathrm{C}, a_{w}=d r y$, and an initial concentration $\left(C_{O}\right)=0.10 \mathrm{~g}$ methyl linoleate/g model system. The headspace oxygen concentrations used were $0.52 \%, 1.05 \%, 2.17 \%$, and $5.49 \%$

4.2.1. Correlation of Oxygen Uptake Values with Diene Conjugation

Oxygen uptake as measured by the oxygen probe (see section 3.2 for description of the method) was compared with the method of diene conjugation as described in section 3.3. Assuming that in the initial stages of the reaction the major oxidation products are conjugated hydroperoxides with an extinction coefficient of 29000, one can follow the build up of the conjugated hydroperoxides spectrophotometrically at $233 \mathrm{~nm}$ (Privett and Blank, 1962). Also, assuming a one to one stoichiometry between peroxide formed and $\mathrm{O}_{2}$ absorbed, the reacted oxygen is easily calculated. The value of the correlation lies in being able to assess whether all oxygen disappearing from the headspace has in fact reacted with the lipids of the model system.

Figures 2,3 , and 4 show the oxidation of the model system at $0.52 \%, 1.05 \%$, and $2.17 \% \mathrm{O}_{2}$ respectively. The solid line in each figure represents the $\mathrm{O}_{2}$ uptake measured by the apparatus and the dashed line represents the $\mathrm{O}_{2}$ uptake as calculated from 
Figure 2

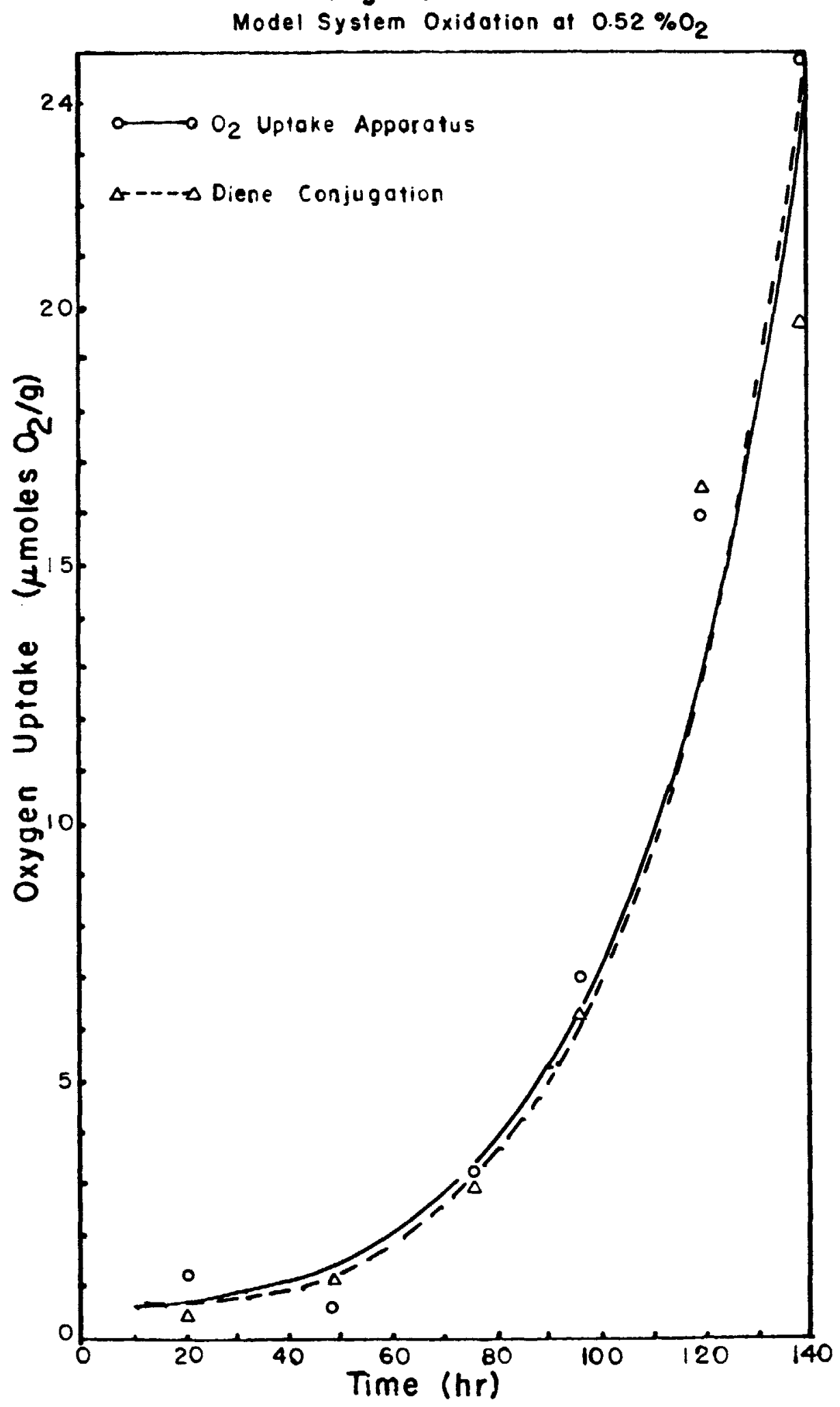


Figure 3

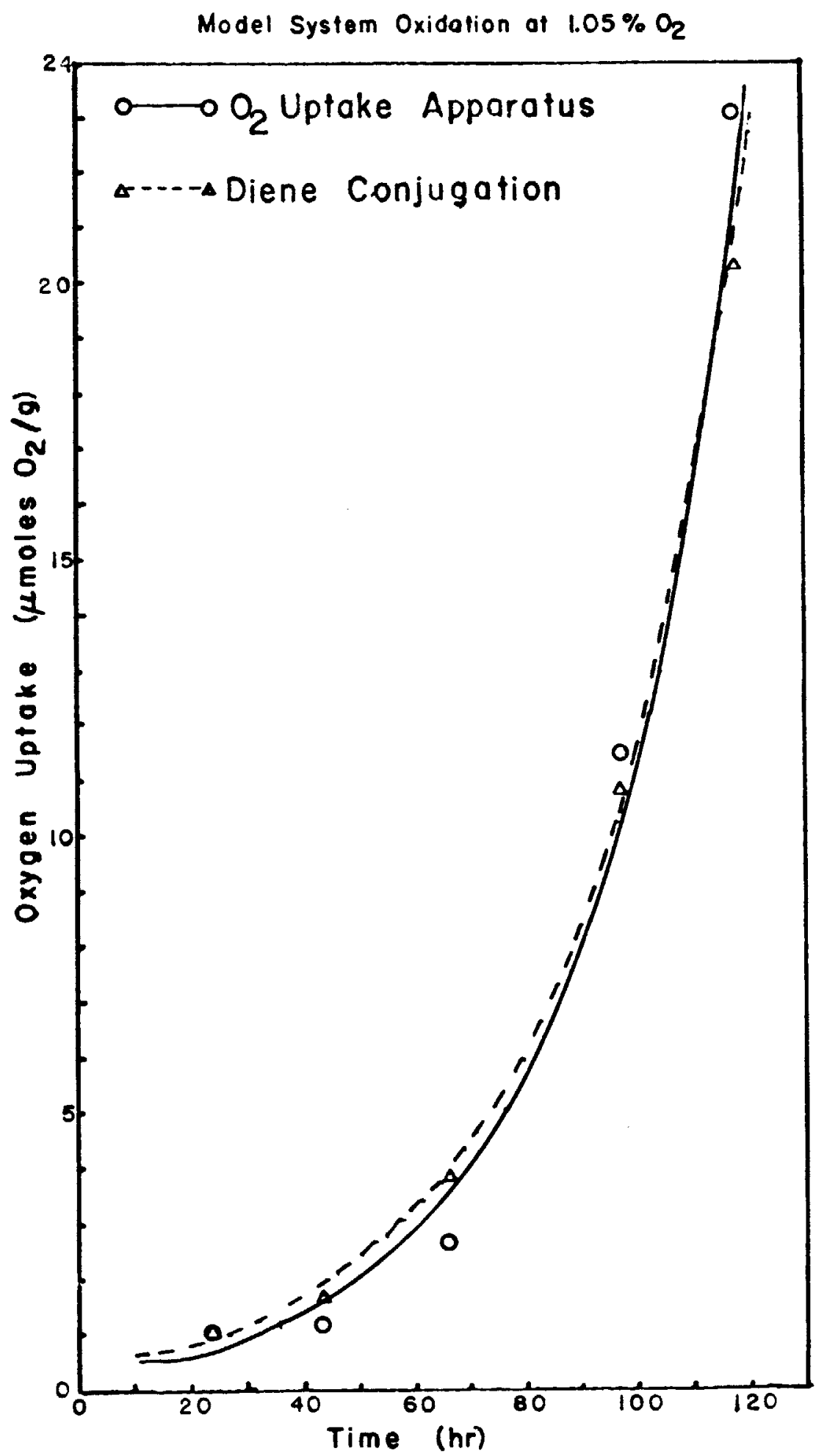


56

Figure 4

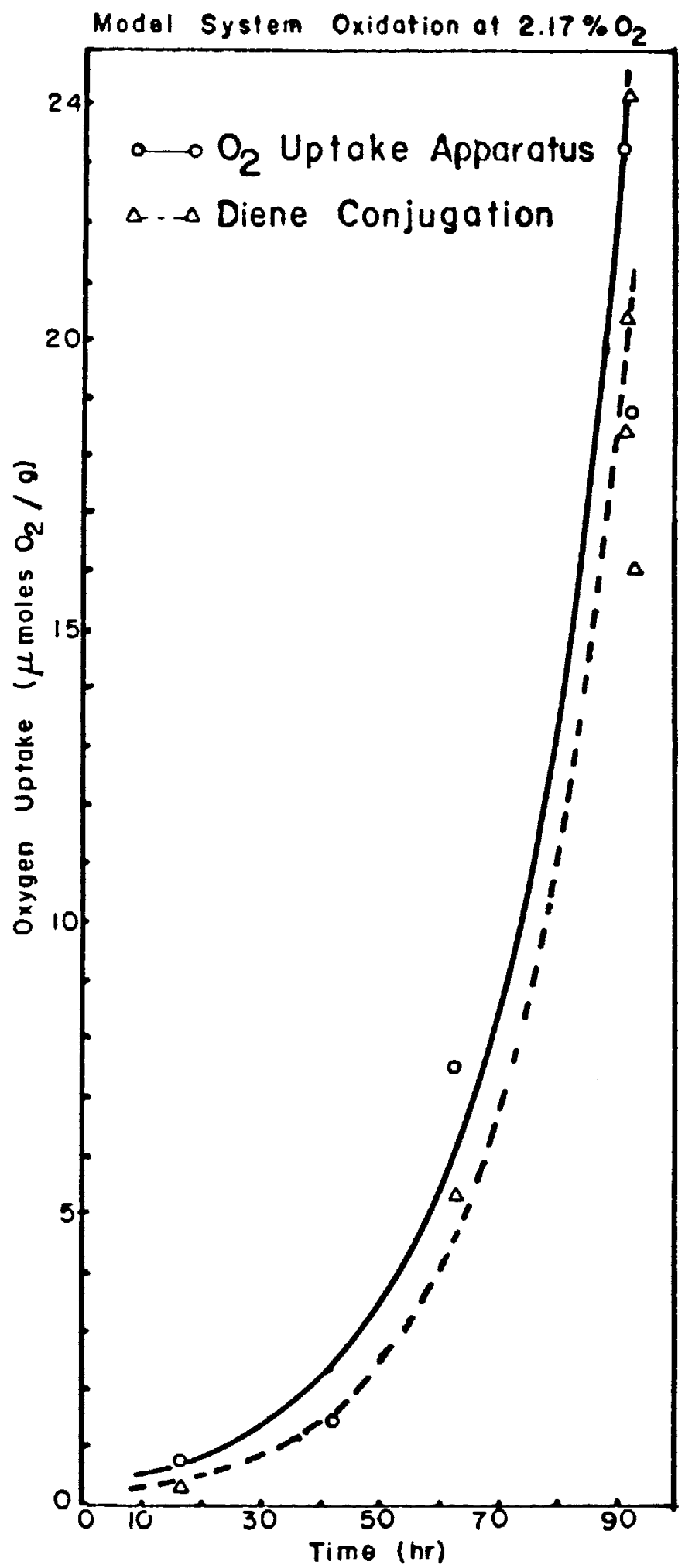


diene conjugation values. The curves were derived using an HP-l1C calculator which linearized the data by taking the natural logarithm of the $\mathrm{O}_{2}$ uptake values and a linear regression on the transformed data to get the constants. The slope of the line is equal to the lst order bimolecular rate constant (See Appendix B for the rate expression). The quality of the fit is determined via the coefficient of determination (see Table 3 for definition of $r^{2}$ ).

Figures 2, 3, and 4 show that the agreement between the two methods is quite good. In order to quantitatively determine how well the two methods compared, oxygen absorption was plotted against the data determined by diene conjugation at each sampling time and the correlation coefficient ( $r$ ) determined. The results of this analysis are shown in Table 2 for the different runs at the four oxygen concentrations studied. It can be seen that the correlation between the two methods is excellent. The correlation coefficients are in the range $.987-.997$. Thus, the method of $\mathrm{O}_{2}$ uptake measurement using an oxygen probe at low concentrations of oxygen correlated extremely well with a chemical method, measuring a major oxidation product. 
Table 2

Correlation Coefficients Between $\mathrm{O}_{2}$ Uptake and Diene Conjugation

\begin{tabular}{cc}
$\mathrm{O}_{2}$ Concentration $(z)$ & Correlation Coefficient \\
\hline 0.52 & .998 \\
& .998 \\
1.05 & .987 \\
& .997 \\
2.17 & .997 \\
& .997 \\
& .996
\end{tabular}

The Correlation coefficient is calculated by,

$$
r=\frac{\sum_{i=1}^{n} x_{i} Y_{i}-\left(\sum_{i=1}^{n} X_{i}\right)\left(\sum_{i=1}^{n} Y_{i}\right) / n}{\sqrt{\left[\sum_{i=1}^{n} x_{i}^{2}-\left(\sum_{i=1}^{n} X_{i}\right)^{2} / n\right]\left[\sum_{i=1}^{n} Y_{i}{ }^{2}-\left(\sum_{i=1}^{n} Y_{i}\right)^{2} / n\right]}}
$$

Where $\left(X_{i}, Y_{i}\right) \ldots\left(X_{n}, Y_{n}\right)$ are the $n$ pairs of observations 


\subsubsection{Kinetic Studies}

The following rate expression was used for determining the bimolecular rate constants at the various oxygen concentrations:

$\mathrm{O}_{2}$ uptake $\left(\mu\right.$ moles $\left.\mathrm{O}_{2} / g\right)=$ Constant $\mu$ moles $\left.\mathrm{O}_{2} / g\right) \times \exp (\mathrm{Kt})$ Where $\mathrm{K}=\mathrm{Bimolecular}$ rate constant $\left(\mathrm{hr}^{-1}\right)$ and $t=$ Time $(h r)$.

See Appendix B for the derivation of this equation.

4.2.2.1. Oxygen Uptake vs Time at $0.52 \%, 1.05 \%, 2.17 \%$, and $5.49 \%$

Table 3 shows the rate constants derived from the rate data for different batches of the model system and the coefficient of determination values for the linearized fit. A reciprocal plot of $1 / \mathrm{K}$ vs. $1 / \% \mathrm{O}_{2}$ for this data is shown in Figure 5 .

As can be seen from Figure 5, a strong oxygen dependence of the rate of oxidation is not indicated, but neither is a straight line, and the scatter in the diagram precludes a quantitative description of the oxygen dependence.

It should be noted that the points on Figure 5 are clustered in pairs of two at each oxygen concentration. This 
Table 3

Rate Constants and $\mathrm{O}_{2} \mathrm{O}_{2}$ Concentrations for Various

Batches of Model System

\begin{tabular}{lllll}
\hline $\mathrm{O}_{2}$ & $1 / 8 \mathrm{O}_{2}$ & $\mathrm{~K}\left(\mathrm{hr}^{-1}\right)$ & $1 / \mathrm{K}(\mathrm{hr})$ & $\mathrm{r}^{2}$ \\
\hline \multirow{2}{*}{0.52} & 1.92 & .037 & 27.03 & .957 \\
& & .031 & 32.26 & .863 \\
& & $.029^{*}$ & 34.48 & .993 \\
1.05 & $.033^{*}$ & 30.30 & .989 \\
& 0.95 & .036 & 27.78 & .972 \\
& & .051 & 19.61 & .988 \\
2.17 & & $.0328^{*}$ & 30.49 & .998 \\
& & $.054^{*}$ & 18.52 & .986 \\
& 0.46 & .0316 & 31.65 & .944 \\
& & .048 & 20.83 & .972 \\
5.49 & & $.0318^{*}$ & 31.45 & .920 \\
& & $.052^{\star}$ & 19.23 & .988 \\
& & .0479 & 20.88 & .963 \\
& & $.0398^{*}$ & 25.13 & .992
\end{tabular}

Æ denotes diene conjugation value.

$r^{2}=$ coefficient of determination, which for the case of an exponential curve $y=a e^{b x}$ is,

$$
r^{2}=\frac{\ln a\left(\Sigma Y_{i}\right)+b\left(\Sigma X_{i} Y_{i}\right)-\left(\Sigma Y_{i}\right)^{2} / n}{\Sigma\left(Y_{i}^{2}\right)-\left(\Sigma Y_{i}\right)^{2} / n}
$$

where $\left(X_{i}, Y_{i}\right) \ldots\left(X_{n}, Y_{n}\right)$ are the $n$ transformed data pairs, i.e., $x_{i}=x_{i}, Y_{i}=\ln y_{i}$. 
Figure 5

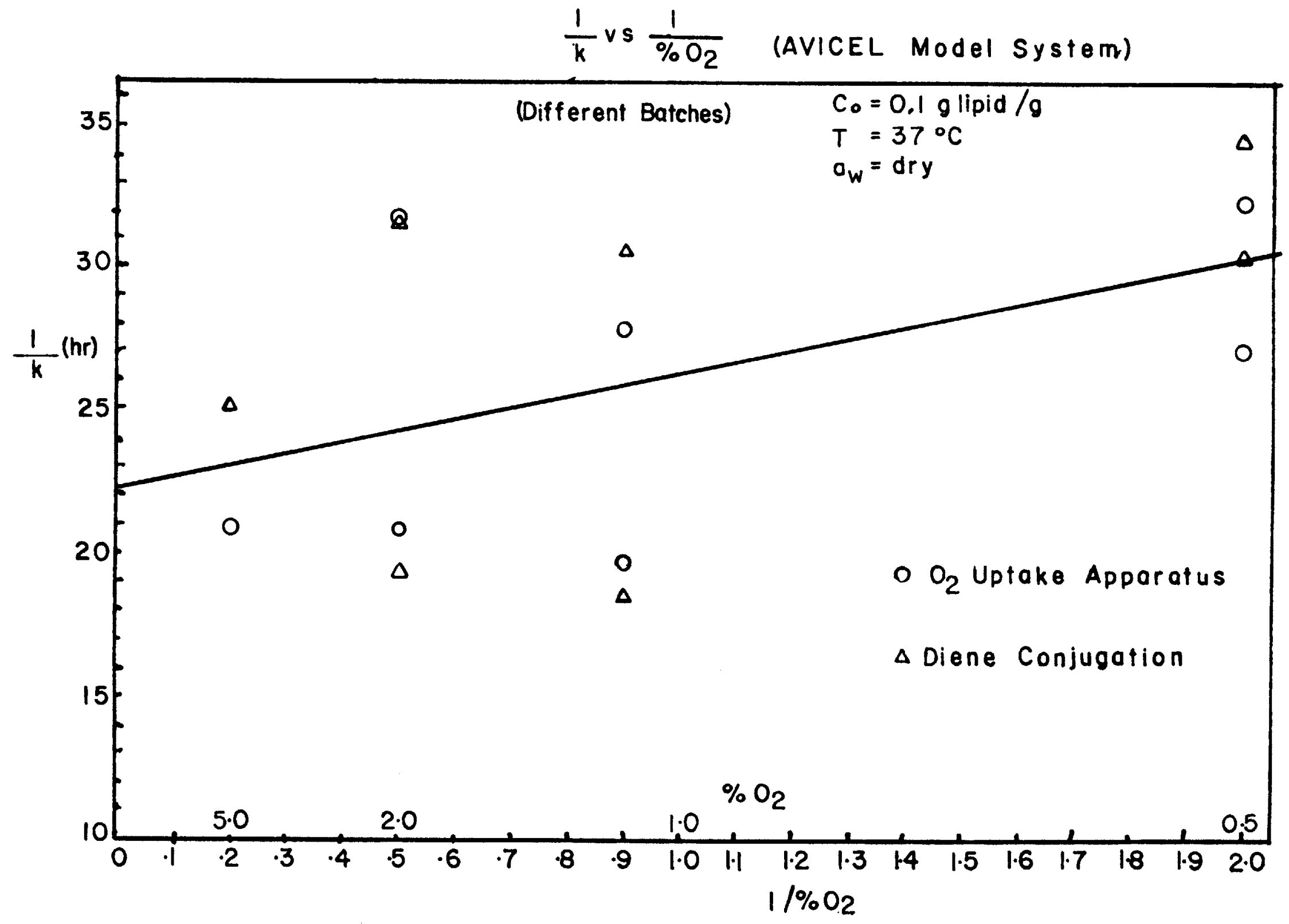


is because each pair represents a kinetic constant derived from oxygen uptake rate data and its corresponding constant from diene conjugation rate data. These pairs were shown in Table 2 to be excellently correlated.

Since the data in Table 3 (and plotted in Figure 5) was drawn from different batches of model system, it was probable that the scatter arose due either to differences in initial purity of the lipid in the different batches or differences in the preparation of the model system.

In order to test the latter two possibilities, oxidation studies were run at the same four $\mathrm{O}_{2}$ concentrations as before, but using a single batch of model system prepared at one time with one fresh sample of methyl linoleate.

The $\mathrm{O}_{2}$ uptake vs time data is plotted in Figure 6 on regular coordinates and as a first order plot on simi-logarithmic coordinates in Figure 7 .

4.2.2.2. Rate Constants as a Function of Percent Oxygen in the Headspace for the Same Batch of Model System

The data plotted in Figures 6 and 7 was analyzed as before and the results listed in Table 4 . 
Figure 6

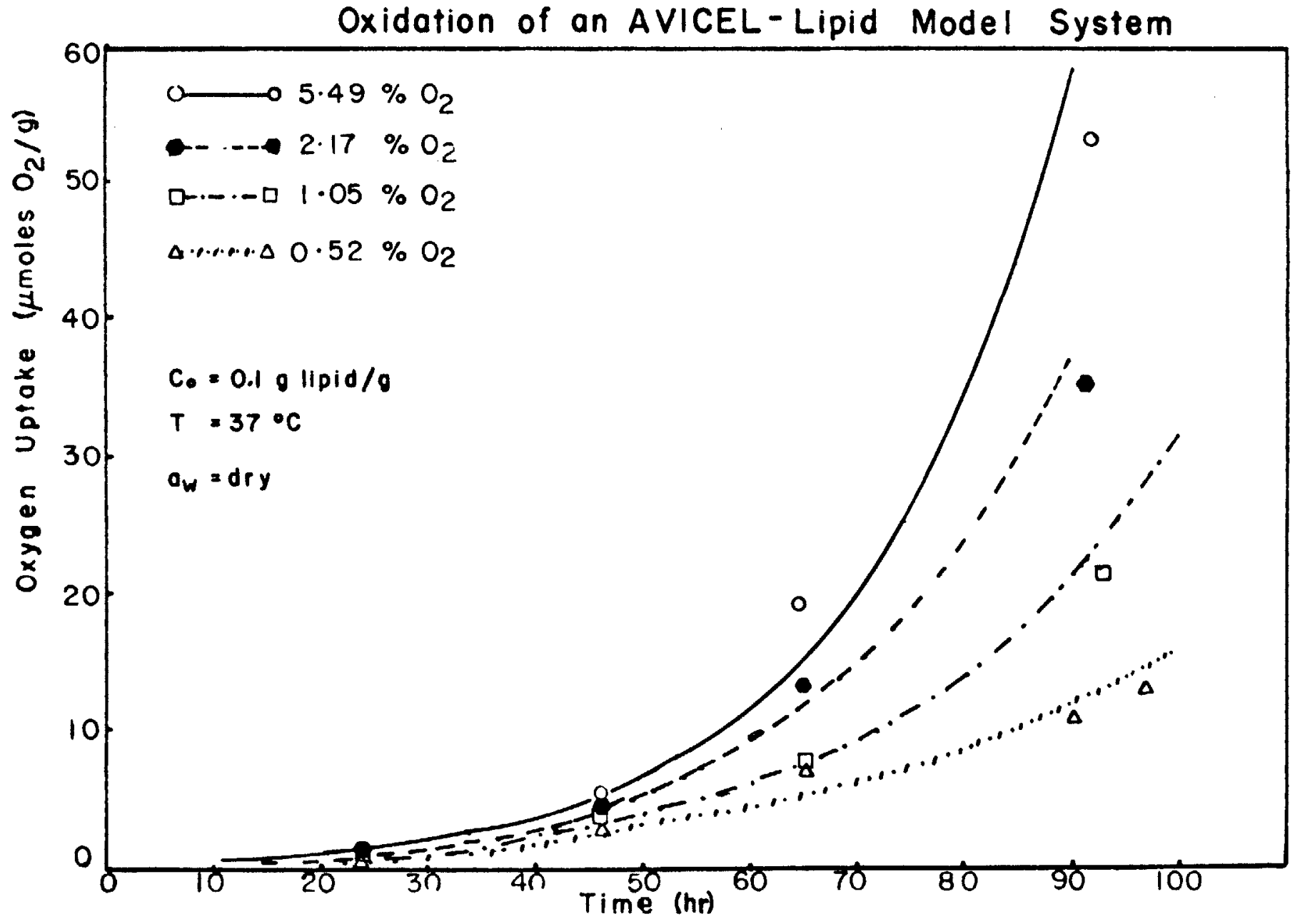




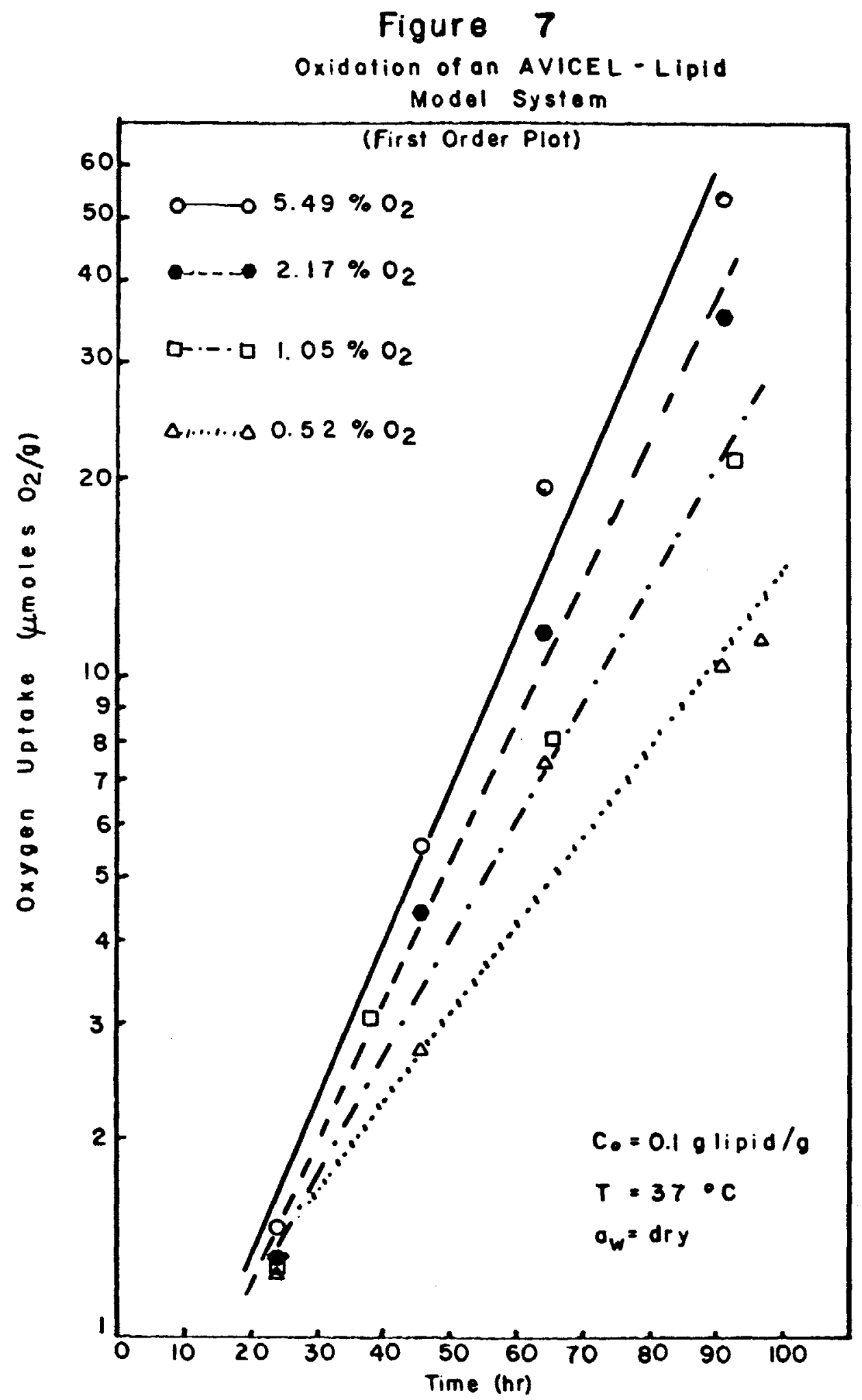


Table 4

Rate Constants and $\mathrm{O}_{2}$ concentrations for the Same Batch of Model System

\begin{tabular}{llcll}
\hline $8 \mathrm{O}_{2}$ & $1 / 8 \mathrm{O}_{2}$ & $\mathrm{~K}\left(\mathrm{hr}^{-1}\right)$ & $1 / \mathrm{K}(\mathrm{hr})$ & $\mathrm{r}^{2}$ \\
\hline 0.52 & 1.92 & .0316 & 31.65 & .957 \\
1.05 & 0.95 & .0412 & 24.27 & .985 \\
2.17 & 0.46 & .0492 & 20.33 & .988 \\
5.49 & 0.18 & .0539 & 18.55 & .983 \\
\hline
\end{tabular}

The data in Table 4 is plotted on reciprocal coordiantes $\left(1 / \mathrm{K}\right.$ vs $\left.1 / 8 \mathrm{O}_{2}\right)$ in Figure 8 . A straight line can easily be drawn through the data and a least squares analysis yields the following equation,

$$
1 / \mathrm{K}=7.59\left(1 / 8 \mathrm{O}_{2}\right)+17.02
$$

with a correlation coefficient $(r)=.9997$. Inverting the above equation to get the direct representation of $K=f\left(\begin{array}{ll}\% & O_{2}\end{array}\right)$ we have,

$$
K=17.02\left(8 O_{2}\right)+7.59
$$


Figure 8

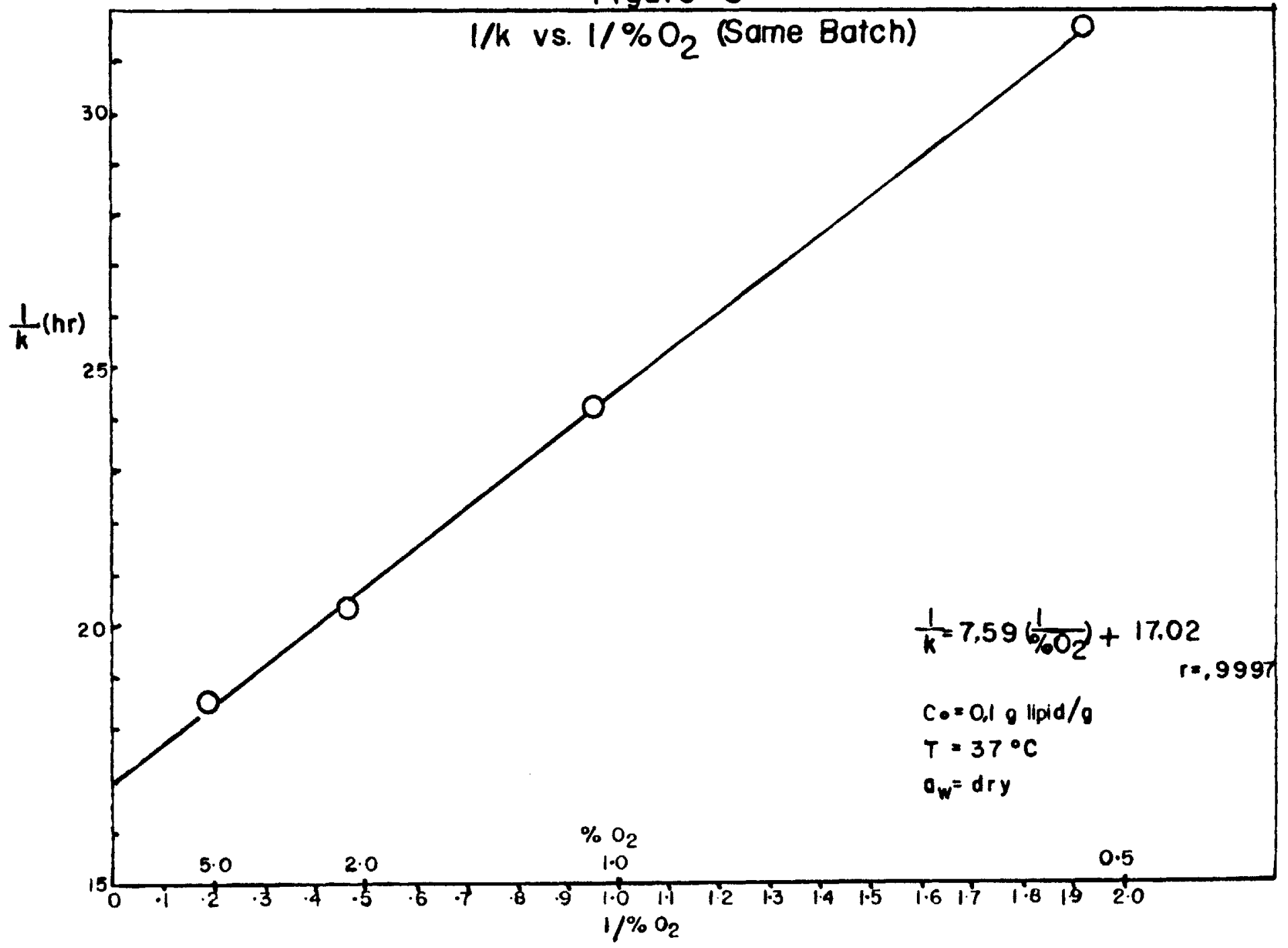


This equation is plotted in Figure 9 where the effect of oxygen concentration on rate is directly seen. Above oxygen concentrations of about $10 \%$, there is essentially no effect on $\mathrm{K}$ of oxygen concentration. Between $\mathrm{O}_{2}$ concentrations of about $3 \%$ to $10 \%$ there is a very slight effect. Below $\mathrm{O}_{2}$ concentrations of $2 \%$, however, the effect on rate is aramatic with the rate decreasing sharply as the $\mathrm{O}_{2}$ concentration is decreased. A linear estimation of the region between $0-5 \% \mathrm{O}_{2}$ gives a slope of roughly $.05 \mathrm{hr}^{-1} / 8 \mathrm{O}_{2}$. A lowering of the oxygen concentration from $.5 \%$ to $.4 \%$ ( $20 \%$ increase) can thus lower the rate constant by $20 \%$.

This effect of almost linear behavior below a certain low $\mathrm{O}_{2}$ concentration has been shown with other systems in the literature (Bateman, 1954; Bolland, 1949; Karel, 1960; Quast and Karel, 1972b).

4.3. Milk System Studies

In order to study the oxidation rate dependence on oxygen concentration in a food system, nonfat dry milk was mixed with methyl linoleate as described in section 3.6.2. This was a harsh treatment (dispersion in methanol) for a food and would, of course, render it unsuitable for human consumption, even after all the methanol had been evaporated. This method of dispersion was chosen, however, because the cellulose model system had been prepared in the same way, thus allowing a more 


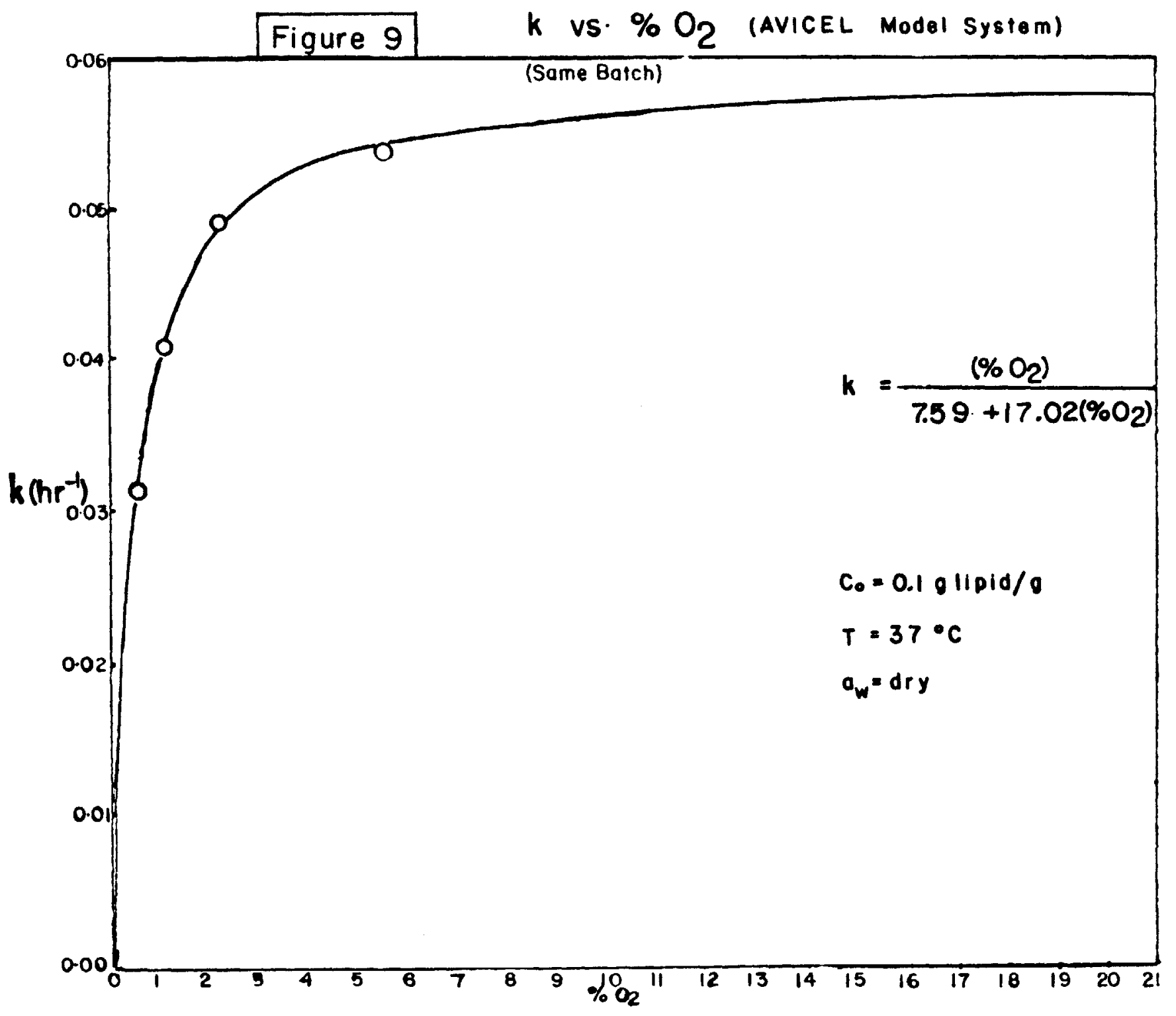

$\infty$ 
meaningful comparison of the results.

Samples were incubated in the dark at $37^{\circ} \mathrm{C}, \mathrm{a}_{\mathrm{w}}=\mathrm{dry}$, and an initial concentration $\left(C_{0}\right)=0.103 \mathrm{~g}$ methyl linoleate $/ \mathrm{g}$ model system. The headspace oxygen concentrations used were $1.05 \%, 2.17 \%, 5.49 \%$, and $10.69 \% \mathrm{O}_{2}$.

since the accuracy of the oxygen uptake apparatus had been checked against the diene conjugation method in the model system (section 4.2.1) and found acceptable, $\mathrm{O}_{2}$ uptake using the oxygen probe was used to follow oxidation. In the milk system, diene conjugation did not give reproducible results. This was due to problems with extraction of the lipid hydroperoxides (conjugated products) from the protein-lactose matrix. Three reasons for this poor extractability were:

1) Encapsulation of the lipids was shown to be operating in this system (section 4.4 .1 ). If any reacted lipids were entrapped or partially entrapped, they might not be extracted with the methanol and would not be measured.

2) Since the protein precipitated during the extraction step, it probably carried conjugated products along with it, thus preventing their spectrophotometric detection.

3) If when the lipid reacted, there was interaction with the protein (this is likely since there was a protein:lipid ratio of approximately $3: 1$ ), then reacted lipid products bound to the protein would not be extracted and would therefore not be measured either. 


\subsubsection{Kinetic Studies}

Figures $10 \mathrm{a}$ and $10 \mathrm{~b}$ show the oxidation of methyl linoleate on nonfat dry milk powder in two separate runs under identical conditions. Figures $11 \mathrm{a}$ and $11 \mathrm{~b}$ show the same data plotted on semi-logarithmic coordinates. The data was treated as described on Appendix B and in sections 4.2 .1 and 4.2 .2 for the model system. The results are tabulated in Table 5 where the coefficient of determination shows the closeness of fit to a first order model.

Overall, it can be seen from Table 5 that the data fit quite well at all oxygen concentrations except for the first run at $1.05 \% \mathrm{O}_{2}$ where $\mathrm{r}^{2}=.761$. In the second run, the reaction was taken farther at $1.05 \% \mathrm{O}_{2}$ and the exponential character of the data becomes more apparent $\left(r^{2}=.976\right.$ for this run) although the rate constant is lower than for the lst run. The results in Table 5 are plotted on reciprocal coordinates of $1 / \mathrm{K}$ vs. $1 / \frac{\circ}{6} \mathrm{O}_{2}$ in Figure 12 . There is some scatter of data apparent and this is probably due to slight differences in preparation of the batches, variations of the milk itself, and the fact that the reciprocal of small numbers are plotted, so small differences in the values are magnified. A straight line has been drawn through this data using a least squares analysis and the resulting expression is,

$$
\begin{array}{r}
1 / K=77.30+75.11\left(1 / 8 O_{2}\right) \\
r=.936
\end{array}
$$


Figure $10 a$

Milk-Methyl Linoleate System Oxidation-1 $1^{\text {st }}$ Run

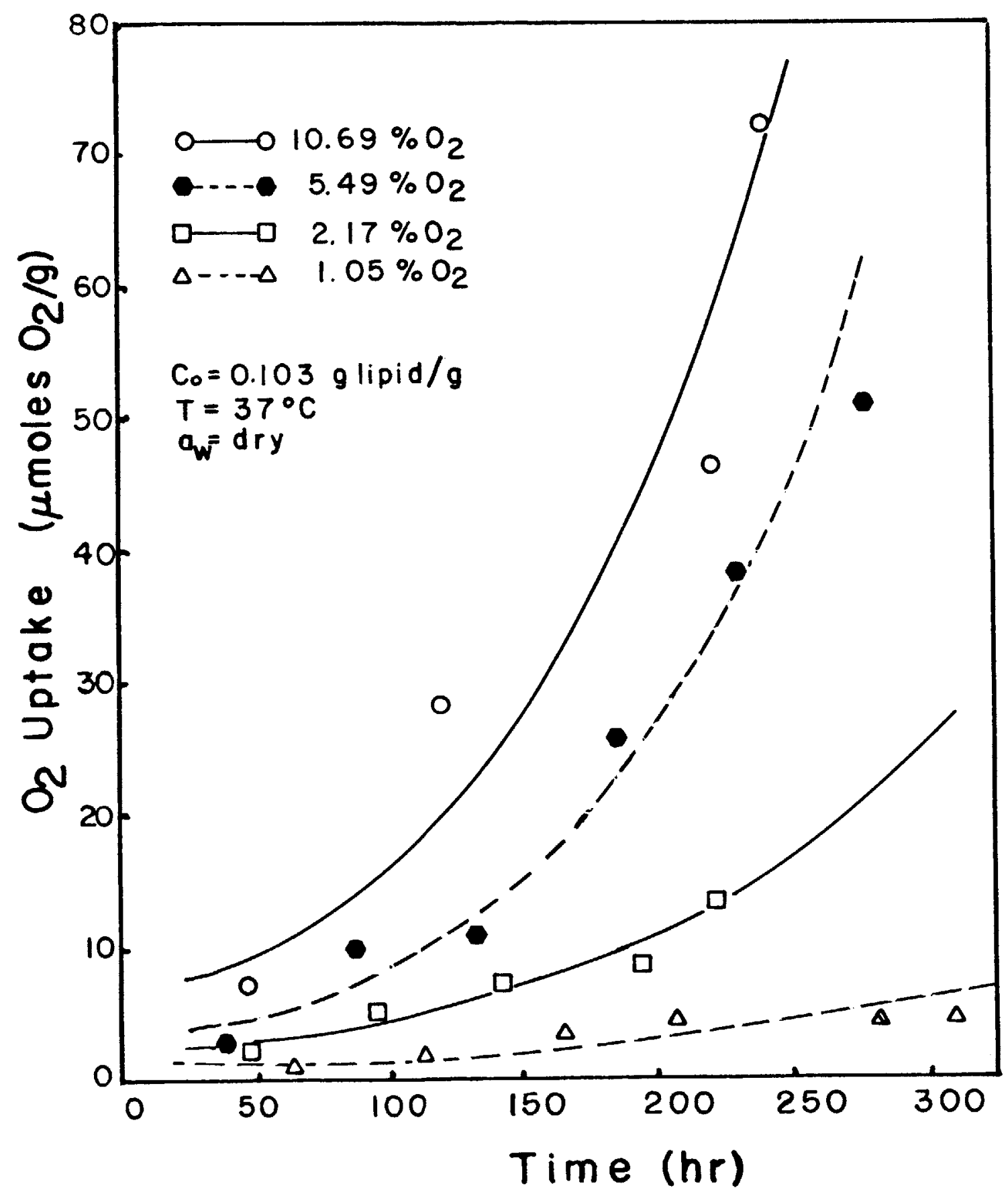


Figure $10 \mathrm{~b}$

Milk - Methyl Linoleate System Oxidation- $2^{\text {nd }}$ Run

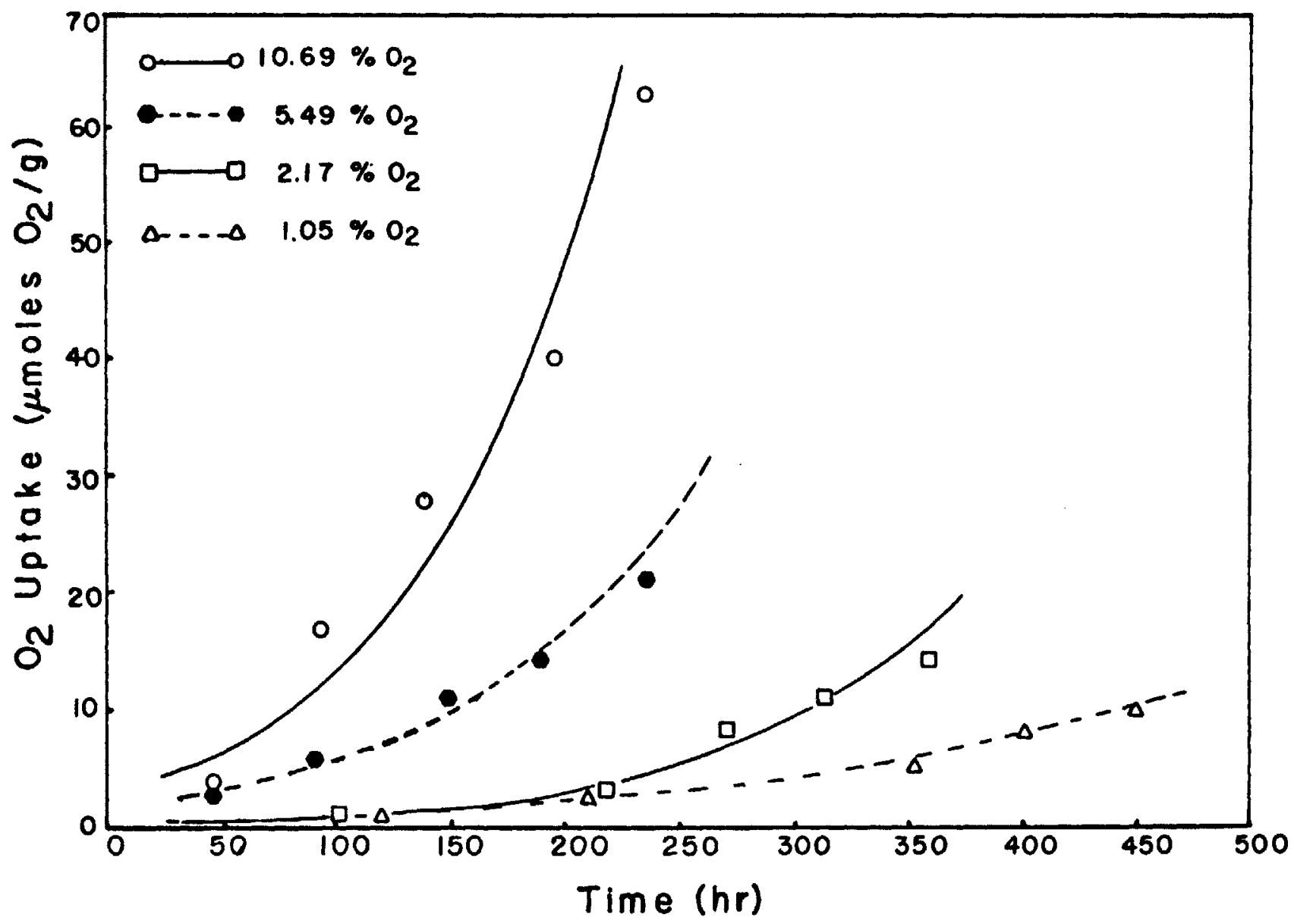


Figure 110

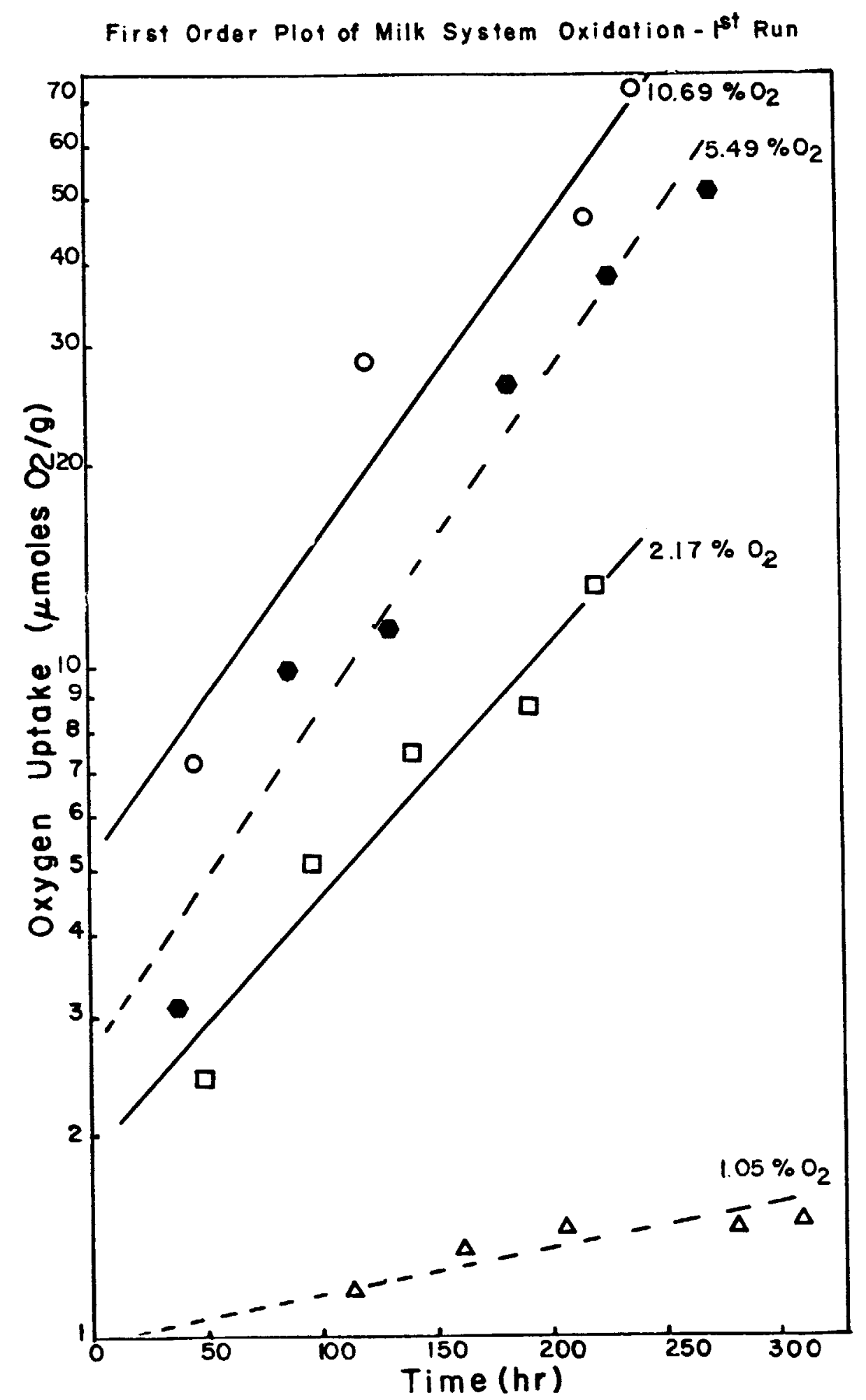


Figure $11 \mathrm{~b}$

First Order Plot of Milk System Oxidation $-2^{\text {nd }}$ Run

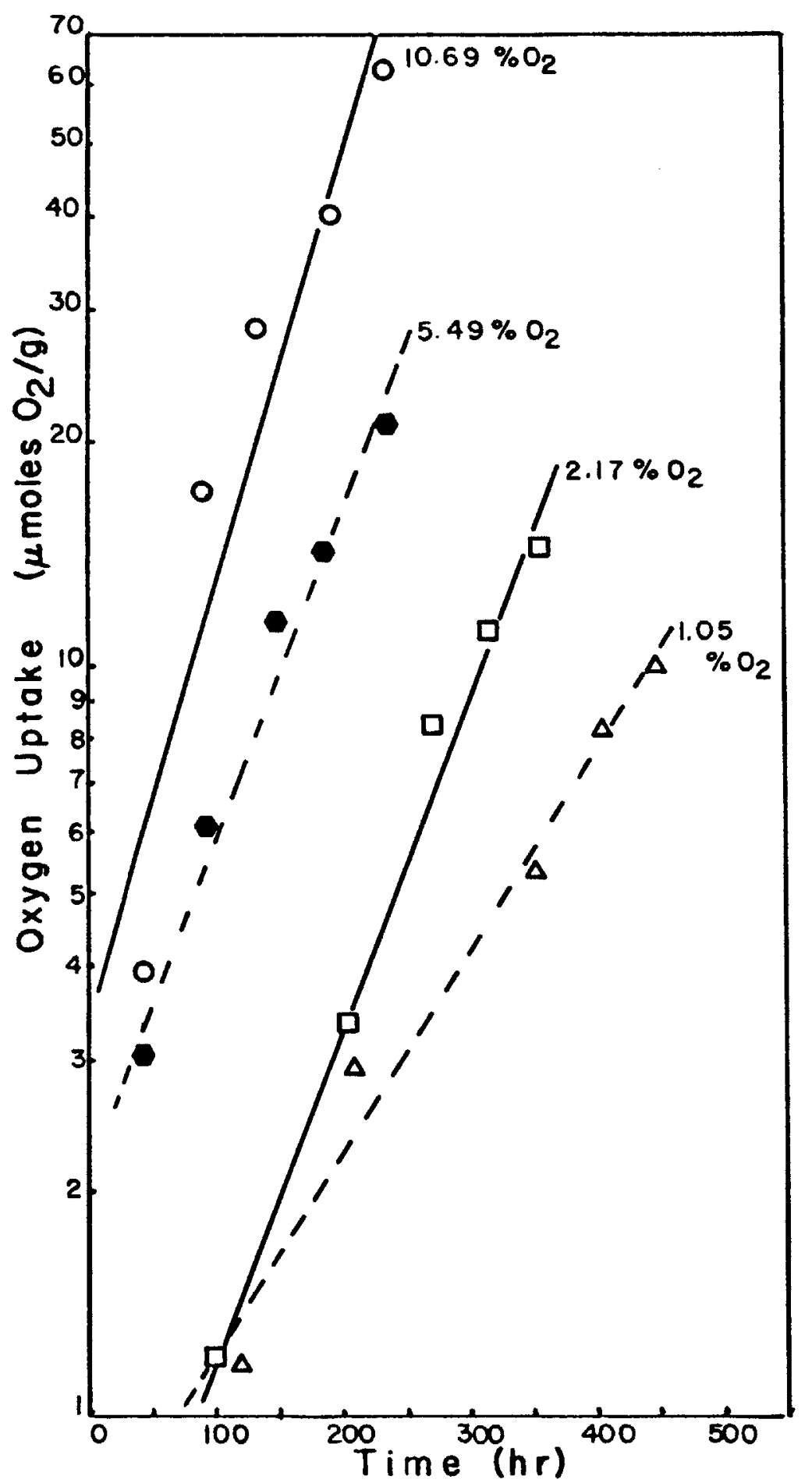


Table 5

Rate Constants and $z \mathrm{O}_{2}$ Concentrations for the Milk-Lipid system

\begin{tabular}{|c|c|c|c|c|c|c|c|c|}
\hline \multirow[b]{2}{*}{$8 \mathrm{O}_{2}$} & \multicolumn{2}{|c|}{$K\left(h r^{-1}\right)$} & \multicolumn{2}{|c|}{$\mathrm{r}^{2}$} & \multirow[b]{2}{*}{$1 / 8 \quad \mathrm{O}_{2}$} & \multicolumn{2}{|c|}{$1 / K(h r)$} & \multirow[b]{2}{*}{ Kavg } \\
\hline & $(1) *$ & $(2) *$ & $(1)$ & $(2)$ & & $(1)$ & $(2)$ & \\
\hline 1.05 & .0071 & .0062 & .761 & .976 & .95 & 140.85 & 161.29 & .0067 \\
\hline 2.17 & .0087 & .0103 & .947 & .977 & .46 & 114.94 & 97.09 & .0095 \\
\hline 5.49 & .0113 & .0101 & .949 & .973 & .18 & 88.50 & 99.01 & .0107 \\
\hline 10.69 & .0105 & .0133 & .926 & .894 & .094 & 95.24 & 75.19 & .0119 \\
\hline
\end{tabular}

*Denotes different runs. 
Figure 12

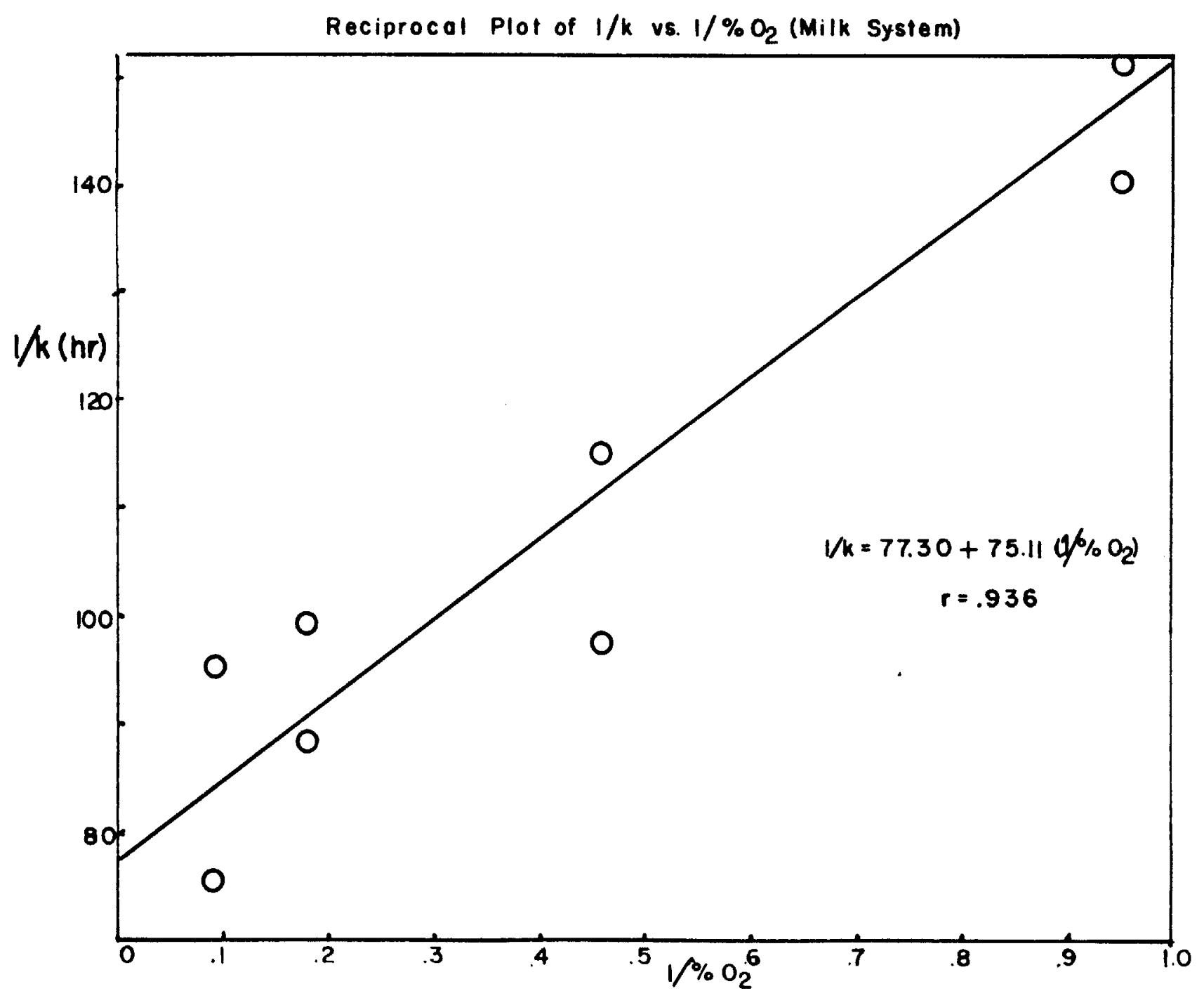


Inverting this equation to get a more direct representation of $\mathrm{K}=\mathrm{f}\left(\mathrm{z} \mathrm{O}_{2}\right)$ yields,

$$
K=\frac{\left(8 \mathrm{O}_{2}\right)}{75.11+77.30\left(\frac{\mathrm{O}_{2}}{2}\right)}
$$

and a plot of the oxygen dependence in this form is shown in Figure 13. In this figure, the average values of $\mathrm{K}$ (last column in Table 5) for the two runs are plotted on the curve which is shown extending down to $0 \% \mathrm{O}_{2}$ and out to $21 \% \mathrm{O}_{2}$. From the curve one can observe that above 9-10\% $\mathrm{O}_{2}$ there is essentially no change in rate with change in $\mathrm{O}_{2}$ pressure. A slight decrease in rate is demonstrated between $5-9 \% \mathrm{O}_{2}$ and below this, the rate-decreasing effect of lowering of the $\mathrm{O}_{2}$ concentration becomes increasingly pronounced.

4.4. Comparison of Model System and Milk System Results

Figure 14 shows a comparison of the oxygen dependence of rate for the two systems studied.

While the general shape of the two curves is similar and the equations fit the data quite well, the rate of oxidation of the two systems is different. The rate constants for the Avicel-lipid system are 5 to 6 times greater than the 


\section{Figure 13}

First Order Constant as a Function of $\% \mathrm{O}_{2}$ (Milk System)

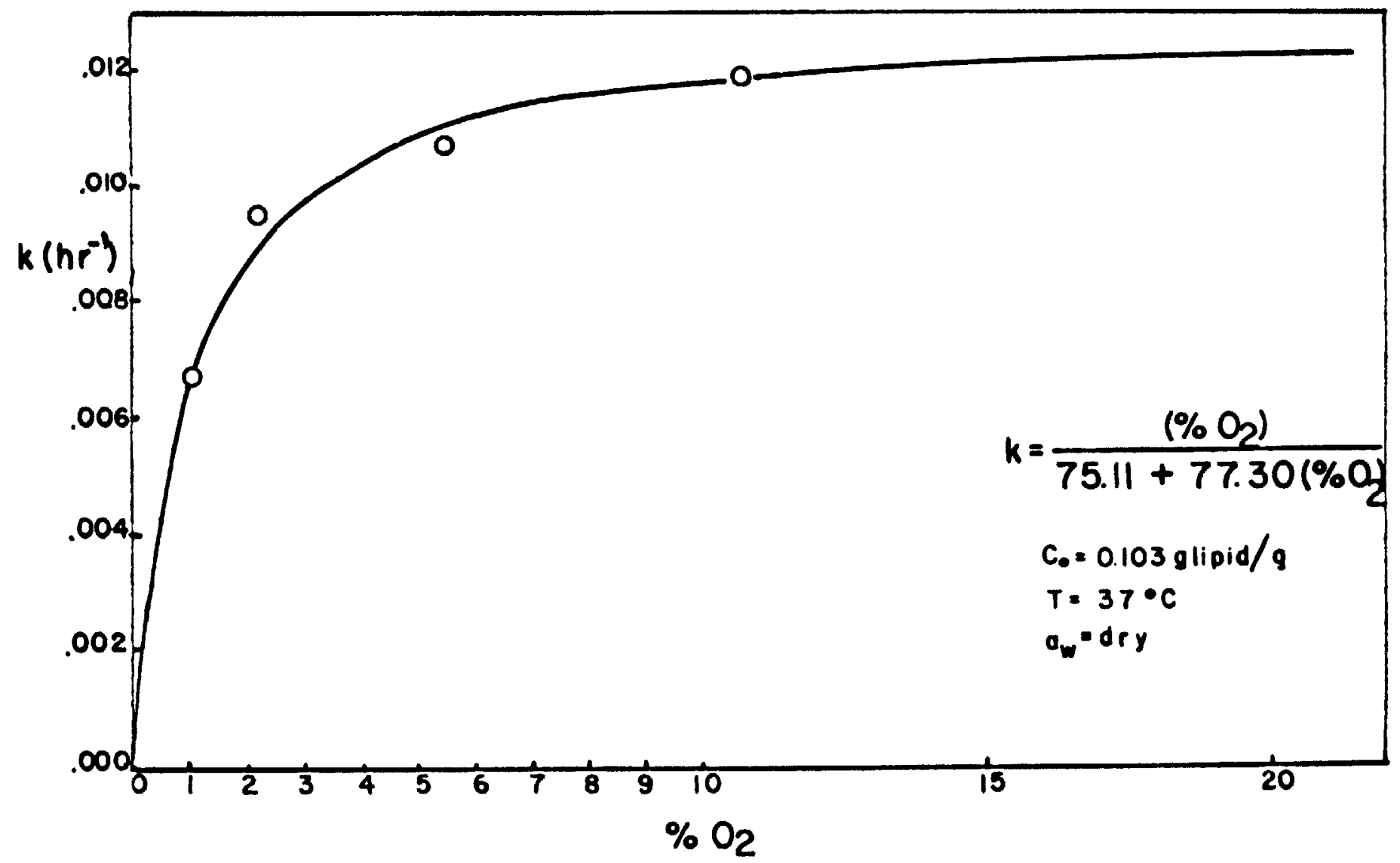


Figure 14

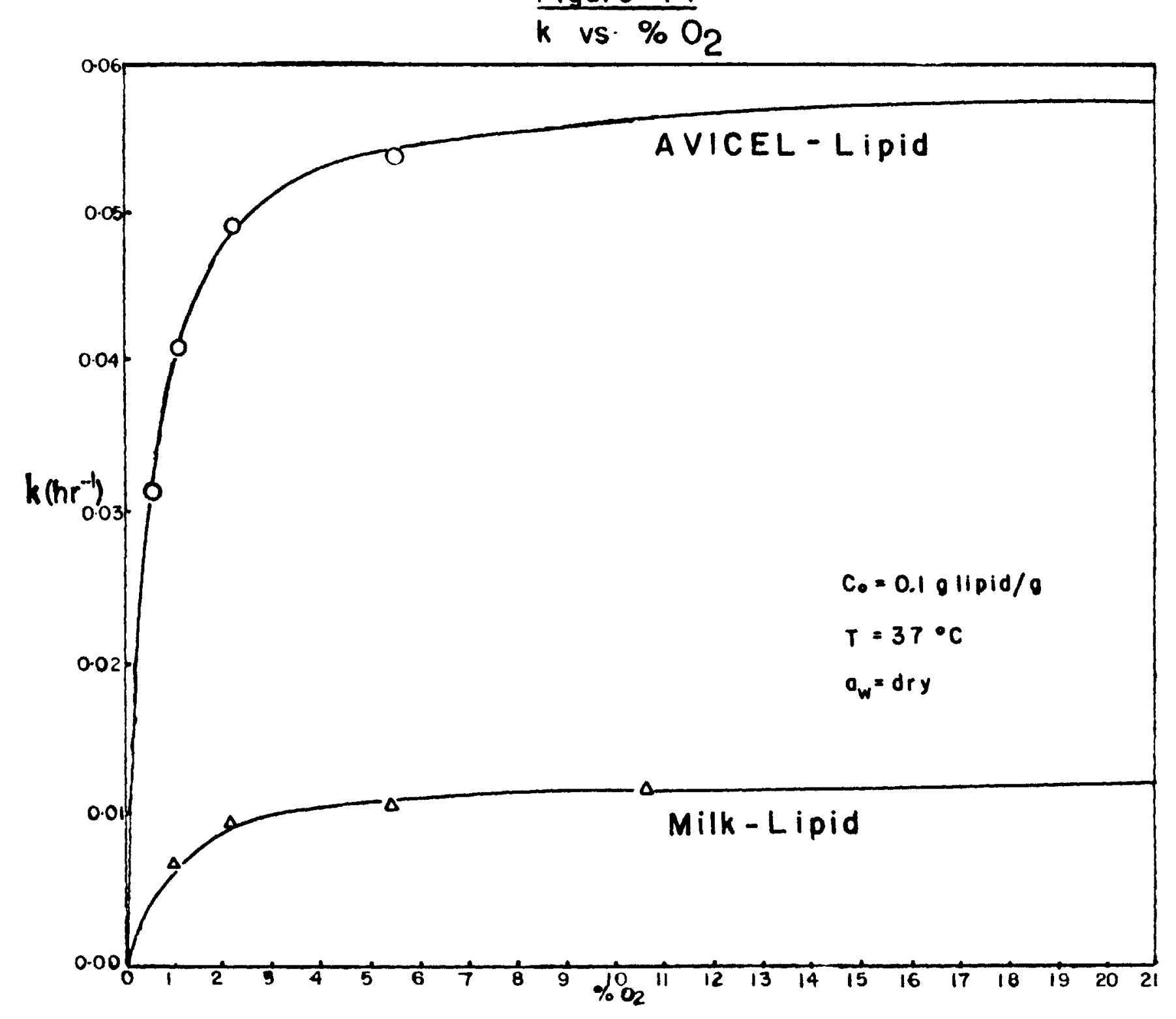


Table 6

Comparison Between Bimolecular Rate Constants Reported in the Literature and Those Observed Experimentally

\begin{tabular}{|c|c|c|c|c|c|}
\hline System & $\mathrm{O}_{2}(8)$ & $\mathrm{T}^{\circ} \mathrm{C}$ & $a_{w}$ & $\mathrm{~K}_{\mathrm{B}}\left(\mathrm{hr} \mathrm{r}^{-1}\right)$ & $\operatorname{Ref}$. \\
\hline $\begin{array}{l}\text { Bulk Methyl } \\
\text { Iinoleate }\end{array}$ & 21 & 40 & - & $6.4 \times 10^{-2}$ & $\begin{array}{l}\text { Kern\& } \\
\text { Dulog, } 1959 a\end{array}$ \\
\hline $\begin{array}{l}\text { Bulk Methyl } \\
\text { Linoleate }\end{array}$ & 21 & 37 & - & $6.6 \times 10^{-2}$ & $\begin{array}{l}\text { Labuza et al., } \\
1969\end{array}$ \\
\hline $\begin{array}{l}\text { Bulk Ethyl } \\
\text { Linoleate }\end{array}$ & 21 & 40 & - & $3 \times 10^{-2}$ & Bateman, 1954 \\
\hline $\begin{array}{l}\text { Methyl } \\
\text { Linoleate in } \\
\text { Emulsion }\end{array}$ & 21 & 40 & - & $8.5 \times 10^{-2}$ & $\begin{array}{l}\text { Marbrouk \& } \\
\text { Dugan, } 1961\end{array}$ \\
\hline $\begin{array}{l}\text { Methyl Linoleate } \\
\text { Cellulose Powder }\end{array}$ & $\begin{array}{l}21 \\
21 \\
21\end{array}$ & $\begin{array}{l}37 \\
37 \\
37\end{array}$ & $\begin{array}{l}\text { dry } \\
.32 \\
.50\end{array}$ & $\begin{array}{l}8.2 \times 10^{-2} \\
5.3 \times 10^{-2} \\
5.0 \times 10^{-2}\end{array}$ & $\begin{array}{l}\text { Labuza et al., } \\
1969\end{array}$ \\
\hline $\begin{array}{l}\text { Methyl Linoleate } \\
\text { Filter Paper }\end{array}$ & $\begin{array}{l}21 \\
21\end{array}$ & $\begin{array}{l}37 \\
37\end{array}$ & $\begin{array}{l}\text { dry } \\
.98\end{array}$ & $\begin{array}{l}4.6 \times 10^{-2} \\
6.8 \times 10^{-2}\end{array}$ & $\begin{array}{l}\text { Labuza et al., } \\
1969\end{array}$ \\
\hline $\begin{array}{l}\text { Methyl Linoleate } \\
\text { Avicel Cellulose }\end{array}$ & $\begin{array}{l}5.49 \\
2.17 \\
1.05 \\
0.52\end{array}$ & $\begin{array}{l}37 \\
37 \\
37 \\
37\end{array}$ & $\begin{array}{l}\text { dry } \\
\text { dry } \\
\text { dry } \\
\text { dry }\end{array}$ & $\begin{array}{l}5.39 \times 10^{-2} \\
4.92 \times 10^{-2} \\
4.12 \times 10^{-2} \\
3.16 \times 10^{-2}\end{array}$ & Present Study \\
\hline $\begin{array}{l}\text { Methyl Linoleate } \\
\text { Nonfat Dry Milk } \\
\text { Powder }\end{array}$ & $\begin{array}{r}10.69 \\
10.69 \\
5.49 \\
2.17 \\
1.05\end{array}$ & $\begin{array}{l}37 \\
37 \\
37 \\
37 \\
37\end{array}$ & $\begin{array}{l}.55 \\
\text { dry } \\
\text { dry } \\
\text { dry } \\
\text { dry }\end{array}$ & $\begin{array}{l}1.99 \times 10^{-2} \\
1.19 \times 10^{-2} \\
1.07 \times 10^{-2} \\
0.95 \times 10^{-2} \\
0.67 \times 10^{-2}\end{array}$ & Present study \\
\hline
\end{tabular}


corresponding constants for the milk-lipid system. The experimental rate constants are displayed in Table 6 along with rate constants for similar systems from the literature.

One would expect that the rate of oxidation of the oil in the milk powder would be lower than the rate on cellulose since the milk contains protein which could interact with the lipid, thus preventing mobility of the fatty acid chains or directly inhibiting free radical propagation.

The rate in the milk system could also be lower due to encapsulation of the lipids in an amorphous lactose-protein matrix preventing $\mathrm{O}_{2}$ from reaching any lipid not on the surface expect by very slow $\mathrm{O}_{2}$ diffusion.

A third possibility is that the surface areas of the two systems were sufficiently different to affect the rate of oxygen uptake.

These latter two physical rate-inhibitory possibilities were tested as described below.

\subsubsection{Encapsulation Effects}

In order to test the possibility that part of the lipid was hidden from $\mathrm{O}_{2}$ and therefore not able to react, an oxidation run was done at $10.69 \% \mathrm{O}_{2}$ with a humidified sample $\left(\mathrm{a}_{\mathrm{w}}=\right.$ .55) and compared to the rate at these conditions in a dry system.

As seen in Table 6 for the methyl linoleate on cellulose 
powder data of Labuza et al. (1969), the rate of reaction of the oxidizing lipid should decrease when going from dry to humid. Only when one goes up to very high moisture contents does the rate begin to increase again (Table 6 shows this effect for methyl linoleate on filter paper in the data of Labuza et al., 1969).

As shown by Saltmarch and Labuza (1980) for whey powder, when the $a_{w}$ increases above .4 , lactose begins to crystallize out and "squeezes" out any material entrapped within the matrix. If lipias were entrapped within the matrix, increasing the $a_{w}$ to .55 should provide mobility for the lactose to rearrange itself into a more thermodynamically favorable state, viz. crystals, and thus expose the previously entrapped lipid to the oxygen envronment. If on the other hand, lipid was not entrapped, increasing $a_{w}$ to .55 would decrease the rate as previously mentioned.

Figure 15 shows the results of this experiment. The samples held at the higher relative humidity oxidized significantly faster than the dry samples. Table 6 lists the experimental rate constants for the dry and humid systems as $1.19 \mathrm{x}$ $10^{-2} \mathrm{hr}^{-1}$ and $1.99 \times 10^{-2} \mathrm{hr}^{-1}$, respectively. It would thus appear that encapsulation of lipid was occurring in the milk system and this was responsible in part for the lower observed rates.

It should be noted that this humidification procedure did not necessarily release all the encapsulated lipid. Also, even 
Figure 15

Comparison of Dry and Humidified Milk System

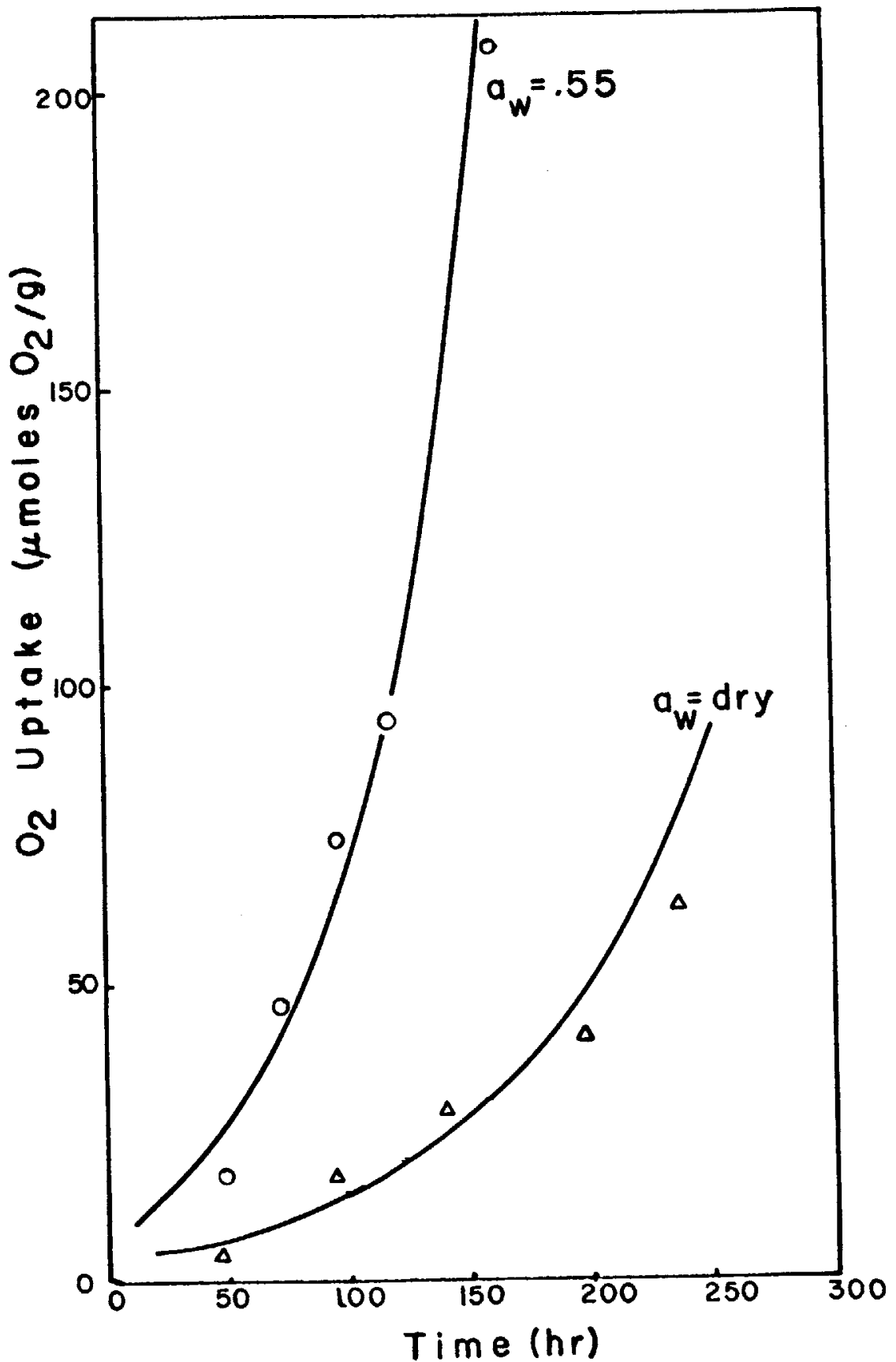


if encapsulation was the sole inhibitory mechanism operating in the milk system, this experiment would not show it. If all the linoleate was released by humidification, the rates would probably still be lower than in the dry model system due to $a_{w}$ effects on oxidation rate.

\subsubsection{Surface Area Effects}

In order to determine the surface area of the milk system, a B.E.T. isotherm was calculated using the nonfat dry milk prepared as in section 3.4 and the surface area determined from the monolayer value. The calculations and isotherms are shown in Appendix C. In order to calculate the surface area by water sorption, the area of a water molecule is assumed to be $10.6 \mathrm{x}$ $10^{-20} \mathrm{~m}^{2}$ (Labuza, 1968). This water surface area is usually very different from surface areas calculated by $\mathrm{N}_{2}$ B.E.T. values or permeability methods; sometimes several orders of magnitude higher. This is because the water molecule is smaller than $\mathrm{N}_{2}$ (or $\mathrm{O}_{2}$ ) and can enter small pores and crevices. Also, the highly polar water molecules can plasticize various long chain polymers that make up the structural matrix, thus exposing more interior sites for adsorption (Stitt, 1958). For these reasons, the surface areas calculated from B.E.T. water sorption values will not give a "true" surface area, however, the surface areas thus derived can be useful for comparison. A surface area of $74.45 \mathrm{~m}^{2} / \mathrm{g}$ was found for the milk system 
by this method. The surface area of the Avicel pH 101 used in the experiment was $138 \mathrm{~m}^{2} / \mathrm{g}$ (private communication, FMC Corporation), or roughly double that in milk.

Stefanovich (1982) showed that the first order rate constant evaluated for $\beta$-carotene oxidation at one Avicel surface area was halved when evaluated on another Avicel of half the surface area.

Since the oxidation studies were performed under dry conditions, it is useful to know whether the B.E.T. surface area calculated in Appendix C corresponded to the area before or after the state of lactose in the system had changed. In other words, is the surface area measured by the B.E.T. isotherm the same as the surface area present in the dry system during oxidation?

As previously stated, Saltmarch and Labuza (1980) found that only above $a_{w} \simeq .4$ did the lactose begin to crystallize. If the last point in the B.E.T. isotherm (corresponding to $a_{w}>$ .4) is neglected and the linear regression done only on those points below $a_{w}=.4$, the resulting monolayer value $\left(v_{m}\right)=$ .021 , i.e. the same as previously found and thus giving the same surface area noted above. The B.E.T. isotherm therefore gives the water surface area in the system of interest, viz. the dry milk powder as it was before collapse.

It might therefore be expected that a significant lowering of the milk system rate constants results merely from the lower surface area of the milk powder compared with the cellulose. 
In summary, both encapsulation effects and surface area effects decreased the rate of reaction of the milk system. Some lipid-protein effects were probably also operative, however, these were not tested for. 


\section{CONCLUSIONS}

1. A method for determination of adsorbed/entrapped oxygen in dehydrated food products was developed which worked on the principle of sample solubilization in deaerated water for release of the residual gases. Measurement of the oxygen was done with an oxygen probe.

2. Using the above method, an average of $3.61 \mu$ moles $\mathrm{O}_{2} / \mathrm{gram}$ nonfat dry milk was found. The coefficient of variation was 20\%. This oxygen content was higher than reported values in the literature for similar systems and was probably due to the lower moisture content of the samples in this experiment.

3. Correlation coefficients in the range .987 - .997 were found between the method of oxygen uptake developed for this work and diene conjugation values.

4. Oxidation in a methyl linoleate-cellulose system was studied at oxygen concentrations of $0.52-5.49 \% \mathrm{O}_{2}$ and in a methyl linoleate-nonfat dry milk system at oxygen concentrations of $1.05-10.69 \% \mathrm{O}_{2} \cdot$

5. A first order model well represented the kinetic data in both systems and bimolecular decomposition of hydroperoxides was 
thus indicated. Comparison of the experimental K's with those in the literature showed the experimental values for the cellulose model system to be within the range of literature values (although lower due to $\mathrm{O}_{2}$ limitation on rate).

6. It was also found that due to encapsulation of lipid in the milk system and a lower surface area of the milk system (compared to the cellulose system), the first order kinetic constants for the milk system were 5 to 6 times lower than for the cellulose system. 
6. SUGGESTIONS FOR FURTHER WORK

1. Methods for determination of sorbed/entrapped oxygen such as the one described herein should be used to determine $\underline{\mathrm{O}}_{2}$ sorption isotherms for different foods at various temperatures and water activities.

2. Studies such as those of Saguy et al. (1983) should be performed on various foods to determine the reason for the desorption behavior of the two types of powders (Type I and Type II) encountered in the saguy et al. study.

3. Kinetic experiments at low oxygen concentrations such as those reported in this work should be performed on various lipid-containing foods at different water activities and temperatures with the aim of developing accelerated tests. 


\title{
7. APPENDICES
}

\author{
Appendix A \\ Calculation of Oxygen Adsorbed/Entrapped in \\ Nonfat Dry Milk Powder
}

As described in the text, no dissolved oxygen was found in any of the samples. The following calculations therefore apply to the gaseous oxygen released from the powder upon sample solubilization and headspace gas compression.

e.g. Sample 5

$$
\begin{aligned}
\text { Sample mass } & =4 \text { grams } \\
\text { Temperature } & =296 \mathrm{~K} \\
\text { Headspace volume } & =1.93 \mathrm{ml}=1930 \mu \mathrm{l} \\
\text { Total pressure } & =1 \text { atm } \\
\text { Probe reading } & =9.74(\mathrm{x} .021) \\
\mathrm{R} & =.08206(\mu \mathrm{l})(\mathrm{atm}) /(\mu \mathrm{mole})(\mathrm{K})
\end{aligned}
$$

Calculations were done using the ideal gas equation:

$$
\Omega\left(\frac{\mu \text { moles } O_{2}}{(\text { gram })}=\frac{p(a t m) \times V(\mu 1)}{R([\mu l)(\text { atm })] /[\mu \text { mole }][K]) \times T(K)} \times \frac{1}{w(\text { gram })}\right.
$$


in this sample

$$
\mathrm{n}=\frac{(9.74)(0.21)(1930)}{(.08206)(296)(4)}=4.06 \frac{\mu \text { moles } O_{2}}{9 \text { ram }}
$$

The results calculated as above are tabulated in Table 1 where an analysis of the standard deviation and coefficient of variation is provided. 


\title{
Appendix B
}

\begin{abstract}
Derivation of the Rate Expression for Lipid Oxidation at Low Oxygen Concentrations
\end{abstract}

Basic Autoxidation Scheme (BAS)

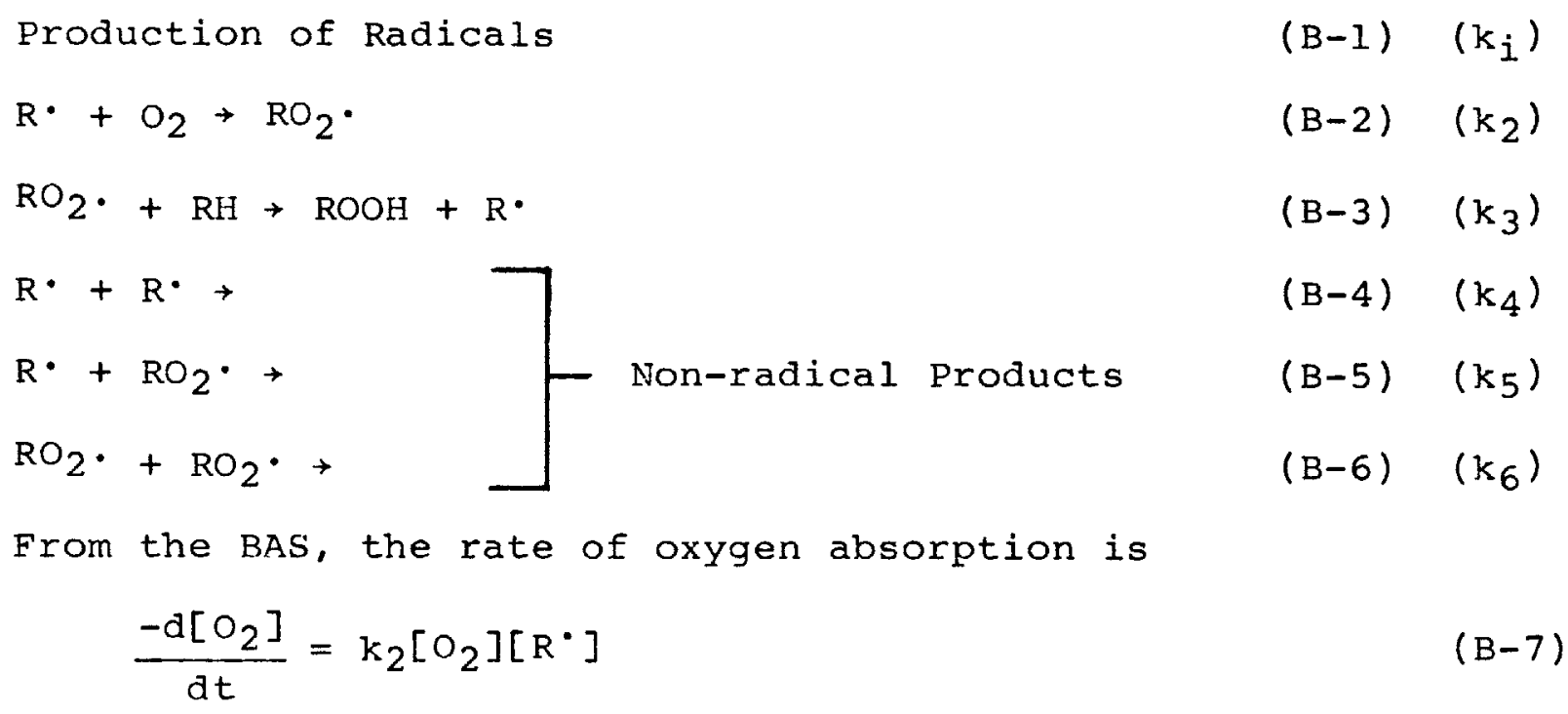

At low concentrations of oxygen, step (B-4) predominates and with the assumption $r_{i}=r_{t}$, we have

$$
\begin{aligned}
r_{i} & =2 K_{4}[R \cdot]^{2} \\
\text { or }\left[R^{\cdot}\right] & =r_{i}^{1 / 2}\left(2 k_{4}\right)^{-1 / 2}
\end{aligned}
$$

Substituting $(B-8)$ into $(B-7)$ :

$$
\frac{-d\left[\mathrm{O}_{2}\right]}{\mathrm{dt}}=\mathrm{k}_{2}\left(2 \mathrm{k}_{4}\right)^{-1 / 2}\left[\mathrm{O}_{2}\right] \mathrm{r}_{\mathrm{i}}^{1 / 2}
$$

Assuming that initiation occurs via bimolecular decomposition of peroxides (valid past an oxidation extent of $1-2 \%$ on a molar 
basis)

$$
r_{i}=k_{i}[\mathrm{ROOH}]^{2}
$$

inserting $(B-10)$ into $(B-9)$

$$
\frac{-d\left[\mathrm{O}_{2}\right]}{\mathrm{dt}}=\mathrm{k}_{2} \mathrm{k}_{\mathrm{i}}\left(2 \mathrm{k}_{4}\right)^{-1 / 2}\left[\mathrm{O}_{2}\right][\mathrm{ROOH}]
$$

$$
\begin{aligned}
& \text { Assuming that } \frac{\frac{-d\left[\mathrm{O}_{2}\right]}{d t}=\frac{d[\mathrm{ROOH}]}{\mathrm{dt}},}{\text { and } \mathrm{K}_{\mathrm{B}}=\mathrm{k}_{2} \mathrm{k}_{\mathrm{i}}\left(2 \mathrm{k}_{4}\right)-1 / 2\left[\mathrm{O}_{2}\right],} \\
& \frac{-d\left[\mathrm{O}_{2}\right]}{d t}=\frac{\frac{\mathrm{d}[\mathrm{ROOH}]}{d t}=\mathrm{K}_{\mathrm{B}}[\mathrm{ROOH}]}{}
\end{aligned}
$$

Under conditions where peroxide decomposition is still not significant,

$$
\text { set } y=[\mathrm{ROOH}] \simeq\left[\mathrm{O}_{2}\right]
$$

then $(B-11)$ becomes

$$
\begin{aligned}
& \text { or } \begin{aligned}
\frac{d y}{d t} & =k_{B} y \\
\int_{y_{0}}^{y^{t}} \frac{d y}{y} & =\int_{0}^{t} k_{B} d t
\end{aligned} \\
& \text { or } \ln \left(\frac{y}{y_{O}}\right)=K_{B} t \\
& \text { or } \quad y=y_{O} e^{K_{B} t}
\end{aligned}
$$

where $\quad Y_{O}=0$ for $[\mathrm{ROOH}]$

$$
\text { or } y_{0}=\left[\mathrm{O}_{2}\right] \text { absorbed at time } t=0 \text { for }\left[\mathrm{O}_{2}\right] \text {. }
$$


Appendix C

\author{
Calculation of Surface Area of Milk Powder Using \\ the B.E.T. Isotherm
}

Section 3.4 describes the procedure used for obtaining the data in Figure 16 and tabulated in Table 7. The procedure below is the standard one described by Labuza (1968).

The B.E.T. equation can be written as:

$$
\frac{a}{(1-a) v}=\frac{1}{v_{m}^{B}}+\left[\frac{a(B-1)}{V_{m}^{B}}\right]
$$

for $a<.5$

Calculation of Monolayer Value

Plotting a/(1-a)V vs a yields a straight line (Figure 17) with

$$
\text { slope }=\frac{(\mathrm{B}-1)}{\mathrm{BV}_{\mathrm{m}}}=44.995
$$

and

$$
\text { intercept }=\frac{1}{V_{m^{B}}}=3.050
$$

as determined by least squares with a correlation coefficient = .998. Solving (C-2) for $B$ and substituting into (C-1) yields $\mathrm{V}_{\mathrm{m}}=.021 \mathrm{~g} \mathrm{H} \mathrm{H}_{2} \mathrm{O} / \mathrm{g}$ powder. 
Figure 16

Nonfat Dry Milk Isotherm-37 ${ }^{\circ} \mathrm{C}$

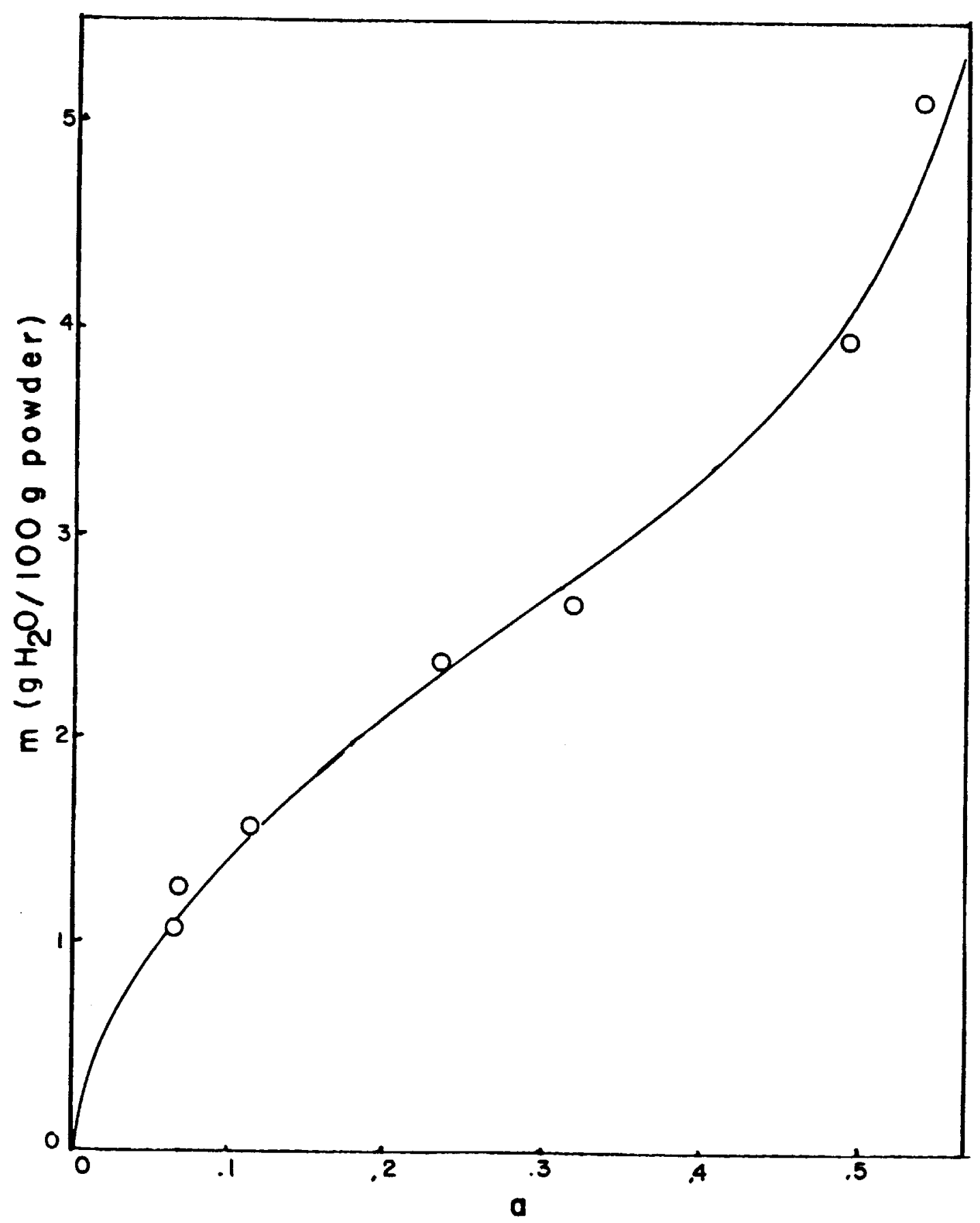




\section{TABLE 7}

Isotherm Data for Determination of B.E.T. Parameters

a $\mathrm{m}\left(\mathrm{g} \mathrm{H} \mathrm{H}_{2} \mathrm{O} / 100 \mathrm{~g}\right.$ powder $) \mathrm{V}\left(\mathrm{g} \mathrm{H}_{2} \mathrm{O} / \mathrm{g}\right.$ powder $) \frac{\mathrm{a}}{(1-\mathrm{a}) \mathrm{V} g \mathrm{~g} \mathrm{H}_{2} \mathrm{O}}$

$\begin{array}{rrrr}.065 & 1.09 & .0109 & 6.38 \\ .066 & 1.29 & .0129 & 5.47 \\ .112 & 1.57 & .0157 & 8.05 \\ .236 & 2.38 & .0238 & 13.01 \\ .318 & 2.60 & .0260 & 17.55 \\ .492 & 3.94 & .0394 & 24.55 \\ .539 & 5.14 & -- & --\end{array}$




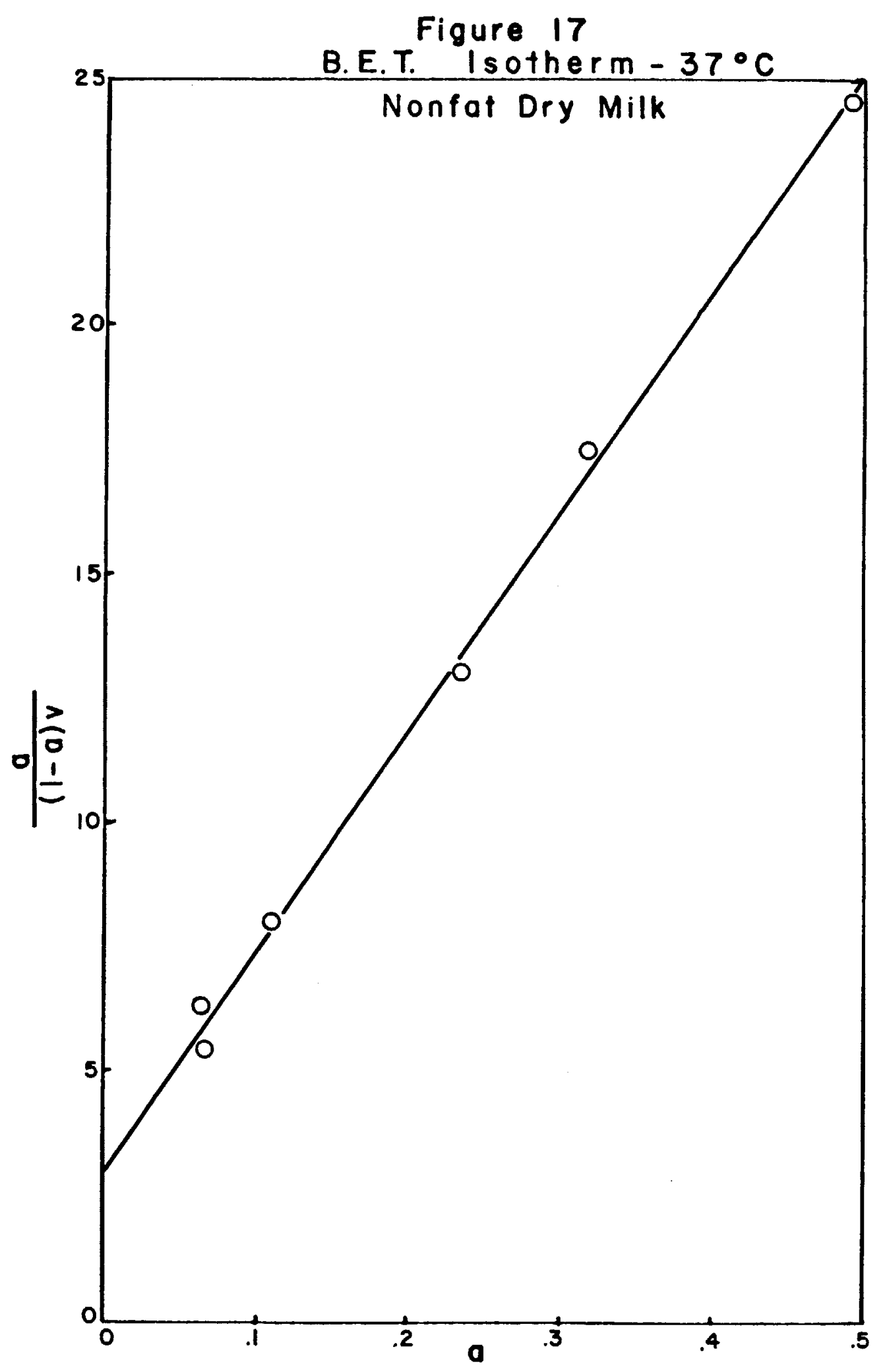


Calculation of Surface Area of Milk Powder

The surface area is given by

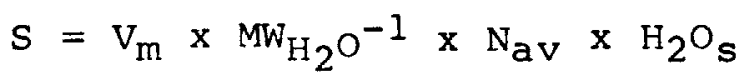

where

$\mathrm{V}_{\mathrm{m}}$ is the monolayer value $\left(\mathrm{g} \mathrm{H}_{2} \mathrm{O} / \mathrm{g}\right.$ powder)

$\mathrm{MW}_{\mathrm{H}_{2}} \mathrm{O}=$ Molecular weight of $\mathrm{H}_{2} \mathrm{O}(\mathrm{g} / \mathrm{mole})$

$\mathrm{N}_{\mathrm{av}}=$ Avogadro's number (molecules/mole)

$\mathrm{H}_{2} \mathrm{O}_{\mathrm{S}}=$ Surface area of $\mathrm{H}_{2} \mathrm{O}\left(\mathrm{m}^{2} /\right.$ molecule $)$

Plugging into $(\mathrm{C}-3)$

$$
\begin{aligned}
S & =(.021) \times\left(18^{-1}\right) \times\left(6.02 \times 10^{23}\right) \times\left(10.6 \times 10^{-20}\right) \\
& =\left(3.54 \times 10^{3}\right)\left(V_{m}\right)=74.45 \mathrm{~m}^{2} / \text { gram. }
\end{aligned}
$$




\section{BIBLIOGRAPHY}

Anonymous, 1967. Laboratory Oxygen Analyzer, Beckman Instruments, Inc., Scientific Instruments Division, Fullerton, CA.

Aceto, N.C., H.I. Sinnamon, E.F. Schoppet, J.C. Craig, R.K. Eskew, 1965. Moisture content and flavor stability of batch vacuum foam-dried whole milk. J. Dairy Sci., $48(5): 544$.

Aceto, N.C., J.C. Craig, R.K. Eskew, F.B. Talley, 1966. 17th International Dairy Congress. Munich Proceedings E, 189.

Bateman, L., 1954. Olefin Oxidation. Quart. Rev. (London) $8: 147$.

Bishov, S.J. and A.S. Henick, 1966. A gas chromatographic method for continuous accelerated study of $\mathrm{O}_{2}$ uptake in fats J. Amer. Oil Chem. Soc., 43.

Bishov, S.J., A.S. Herick, J.W. Giffee, I.T. Nii, P.A. Prell, M. Wolf, 1971. Quality and stability of some freeze-dried foods in "zero" oxygen headspace. J. Food Sci. 36: 532.

Bolland, J.L., 1946. Kinetic studies in the chemistry of rubber and related materials. I. The thermal oxidation of ethyl linoleate. Proc. Roy. Soc. (London), Al86: 218.

Bolland, J.L. and G. Gee, 1946. The kinetics of oxidation of unconjugated olefins. Trans. Faraday Soc. 42: 236.

Bolland, J.L., 1949. Kinetics of olefin oxidation. Quart. Rev. (London) 3: 1 .

Borkowski, J.D. and M.J. Johnson, 1967. Long-lived steamsterilizable membrane probes for dissolved oxygen measurement. Biotech. Bioeng. 9(4): 635 .

Capietti, G.P., G.F. Majorino, M. Zucchetti, A. Marchesini, 1977. Enzymatic microdetermination of oxygen for the control of oxidation in aqueous solutions. Anal. Bioch. 83 : 394 .

Clark, L.C. Jr., R. Wolf, D. Cranger, Z. Taylor, 1953. Continuous recording of blood oxygen tensions by polarography. J. Appl. Physiol. 6: 189 .

Cornell, D.G., E.D. de Vilbiss, M.J. Pallansch. 1971. Binding of antioxidants by milk proteins. J. Dairy Sci. 54(5): 634 . 
Coulter, S.T., R. Jenness, W.F. Geddes. 1951. Physical and chemical aspects of the production, storage, and utility of dry milk products. Adv. Food Res. 3: 451.

Fioriti, J.A., H.D. Stahl, J. Cseri, R.J. Sims. 1975. Chemical and organoleptic properties of dried emulsions. J. Amer. Oil Chem. Soc. 52(10): 395 .

Fioriti, J.A. 1977. Measuring flavor deterioration of fats, oils, dried emulsions, and foods. J. Amer. Oil Chem. Soc. $54(10): 450$.

Fischer, J. and J.C. Deng. 1977. Catalysis of lipid oxidation: A study of Mullet (Mugil cephalus) dark flesh and emulsion model system. J. Food Sci. 42(3): 610 .

Flynn, D.S., D.C. Kilburn, M.D. Lilly, F.C. Webb. 1967. Modifications to the Mackereth oxygen electrode. Biotech. and Bioeng. 9(4): 623 .

Gilbert, T.D., Beymer, H.B. Castaneda. 1982. Determination of dissolved oxygen in natural and wastewaters. American Laboratory, March 1982: 119.

Halback, S. 1977. Catalase activity measured with a micro oxygen electrode in a pressurized reaction vessel. Anal. Bioch. 80: 383 .

Haller, H.S. and G.E. Holm. 1947. The removal of the sorbed gases in dried milks. J. Dairy Sci. 30: 197.

Heinzle, E. and R.M. Lafferty. 1980. Continuous mass spectrometric measurement of dissolved $\mathrm{H}_{2}, \mathrm{O}_{2}$, and $\mathrm{CO}_{2}$ during chemolithoautotrophic growth of Alcaligenes eutrophus strain Hl6. Europ. J. Appl. Microbiol. Biotechnol. $11: 17$.

Henderson, J.L. and H.A. Young. 1942. Some aspects of the rate of reaction of oleic acid with oxygen. J. Phys. Chem. 46: 670 .

Hetrick, J.H. and P.H. Tracy. 1948. Manometric measurement of the gas desorbed from vacuumized whole milk powder. J. Dairy Sci. 31: 831.

Hospodka, J. and Z. Caslavsky. 1964. Design and application of electrodes for the determination of dissolved oxygen. Scientific Instruments, pp. 186-198. From Department of Technical Microbiology, Institute of Microbiology, Czechoslovak Academy of Sciences, Prague, 4. 
Johnson, M.J., J. Borkowski, C. Engblom. 1964. Steam sterilizable probes for dissolved oxygen measurement. Biotech. Bioeng. 6: 457 .

Karel, M. 1960. Some effects of water and of oxygen on rates of reactions of food components. Ph.D. Thesis, Nutrition and Food Science Department, MIT.

Karel, M., P. Issenberg, L. Ronsivalli, V. Jurin. 1963. Application of gas chromatography to the measurement of gas permeability of packaging materials. Food Technol. $17(3): 91$.

Kern, V.W. and L. Dulog. 1959a. J. Makro. Chem. 29: 199.

Kern, V.W. and L. Dulog. 1959b. J. Makro. Chem. 29: 208.

Kok, R. and J.E. Zajic. 1973. Transient measurement of low dissolved oxygen concentrations. Can. J. Chem. Eng. $51(12): 782$.

Kontson, A., A Tamsma, M.J. Pallansch. 1969. Peroxide increase in fat of milk during foam-spray-dried powder manufacture. J. Dairy Sci. 52(5): 615 .

Krebs, W.M. and I.A. Haddad. 1972. The oxygen electrode in fermentation systems. IN: Developments in Industrial Microbiology. Chap. 11, Soc. Ind. Microbiol. Publ.

Labuza, T.P., H. Tsuyuki, M. Karel. 1968. Kinetics of linoleate oxidation in model systems. J. Amer. Oil Chem. Soc. $46(8): 409$.

Labuza, T.P. 1968. Sorptin phenomena in foods. Food Technol. $22(3): 15$.

Labuza, T.P. 1971. Kinetics of lipid oxidation in foods. CRC Crit. Rev. Food Technol.

Labuza, T.P., N.D. Heidelbaugh, M. Silver, M. Karel. 1971. oxidation at intermediate moisture contents. J. Amer. oil Chem. Soc. $48(2): 86$.

Mack, T.E., D.R. Heldman, R.P. Singh. 1976. Kinetics of oxygen uptake in liquid foods. J. Food Sci. 4l(2): 309 .

Maloney, J.F., T.P. Labuza, D.H. Wallace, M. Karel. 1966. Autoxidation of methyl linoleate in freeze-dried model systems. I. Effect of water on the autocatalyzed oxidation. J. Food Sci. $31(6): 878$. 
Marcuse, R., K. Remi, P.O. Gothe. 1964. Fette, Seifen, Anstrichmittel 66: 992 .

Marcuse, R. and P. Fredriksson. 1968. Fat oxidation at low oxygen pressure. I. Kinetic studies on the rate of fat oxidation in emulsions. J. Amer. Oil Chem. Soc. 45(5): 400 .

Marcuse, R. and P. Fredriksson. 1969. Fat oxidation at low oxygen pressure. II. Kinetic studies on Iinoleic acid oxidation in emulsions in the presence of antioxidants. J. Amer. Oil Chem. Soc. 46(5): 262 .

Marcuse, R. 1967. The influence of oxygen partial pressure on fat oxidation. Report No. 231, SIK (Swedish Institute of Fodo Preservation).

Muers, M.M., E.B. Anderson. 1944. Determination of the volume of gas contained in the particles of dried milk powder. Analyst 69: 5 .

Parks, O.W., N.P. Wong, C.A. Allen, D.P. Schwartz. 1969. 6-Trans-nonenal: An off-flavor component of foam-spraydried milks. J. Dairy Sci. 52(7): 953 .

Petering, H.G. and F. Daniels. 1938. The determination of dissolved oxygen by means of the dropping mercury electrode, with applications in biology. J. Amer. Oil Chem. Soc. 60: 2796.

Pominski, J., H.M. Pearce, Jr., H.L.E. Vix, J.J. Spadaro. 1975. Improvement of shelf life of partially defatted peanuts by intromission of nitrogen into the interstices of the peanuts. J. Food Sci. 40(1): 192 .

Privett, O.S. and M.L. Blank. 1962. The initial stages of autoxidation. J. Amer. Oil Chem. Soc. 31(11): 465 .

Pungor, E., C.R. Perley, C.L. Cooney, J.C. Weaver. 1980. Continuous monitoring of fermentation outlet gas using a computer coupled MS. Biotechnology Letters 2(9): 409 .

Quast, D.G. and M. Karel. 1971. Effects of oxygen diffusion on oxidation of some dry foods. J. Food Technol. 6: 95.

Quast, D.G. and M. Karel. 1972a. Technique for determining oxygen concentration inside packages. J. Food Sci. 37: 490 .

Quast, D.G. and M. Karel. 1972b. Effects of environmental factors on the oxidation of potato chips. J. Food Sci. $37: 584$. 
Quast, D.G. and M. Karel. 1972C. Development of a mathematical model for oxidation of potato chips as a function of oxygen pressure, extent of oxidation, and equilibrium relative humidity. J. Food Sci. 37: 673 .

Ramstack, J.M., E.B. Lancaster, R.J. Bothast. 1979. Gas chromatographic headspace analysis of solid substrate fermentations. Process Biochem. 14(2).

Rees, D.U.H. 1981. Apparatus for measuring the oxygen content and temperature of silage. J. Agric. Eng. Res. 26: 185 .

Reuss, M., H. Piehl, F. Wagner. 1975. Application of mass spectrometry to measurement of dissolved gases and volatile substances in fermentation. Europ. J. Appl. Microbiol. 1: 323 .

Riemer, J. 1977. Predictions of vitamin C retention in a stored dehydrated food. Sc.D. Thesis. Nutrition and Food Science Department, MIT.

Rutchi, G., I.J. Dunn, J.R. Bourne. 1981. Comparison of dynamic oxygen electrode methods for the measurement of $\mathrm{K}_{\mathrm{L}} \mathrm{a}$. Biotech. Bioeng. 23: 227 .

Rutgers, R. 1957. Residual gas and the gas packing of milk powder. Neth. Milk Dairy J. 11: 244.

Saguy, I., M. Goldman, B. Horev, M. Karel. 1983. An improved method for the determination of adsorbed/entrapped gases on dehydrated foodstuffs. Submitted for publication.

Saltmarch, M. and T.P. Labuza. 1980. Influence of relative humidity on the physicochemical state of lactose in spraydried sweet whey powders. J. Food Sci. 45(5): 1231 .

Sidwell, C.G., H. Salwin, R.B. Koch. 1962. The molecular oxygen content of dehydrated foods. J. Food Sci. 27: 255 .

Spiehler, V. 1971. Predict oil stability. Food Eng. 43(8): 77 .

Stitt, F. 1958. Moisture equilibrium and the determination of water content of dehydrated foods. Chapter in

"Fundamental Aspects of the Dehydration of Foods." Soc. Chem. Industry, London.

Tamsma, A., M.J. Pallansche, T.J. Mucha, W.I. Patterson. 1961. Factors related to the flavor stability of foam dried whole milk. I. Effect of oxygen level. J. Dairy Sci. $44(9): 1644$. 
Tamsma, A. and M.J. Pallansch. 1964. Factors related to the storage stability of foam-dried whole milk. IV. Effect of powder moisture content and in-pack oxygen content at different temperatures. J. Dairy Sci. 47(9): 970 .

Tamsma, A., F.E. Kurtz, M.J. Pallansch. 1967. Effect of oxygen removal technique on flavor stability of low-heat foam spray-dried whole milk. J. Dairy Sci. 50(10): 1562 .

Teixeira-Neto, R.O. 1978. Oxygen uptake and loss of quality in a dehydrated food model at low oxygen concentrations. S.M. Thesis. Nutrition and Food Science Department, MIT.

Teixeira-Neto, R.O., M. Karel, I. Saguy, S. Mizrahi. 1981. Oxygen uptake and $\beta$-carotene decoloration in a dehydrated food model. J. Food Sci. $46(3)=665$.

Toumy, J.M. and L.C. Hinnergardt. 1968a. Effect of headspace oxygen on the quality of freeze-aried beef and chicken stew. Technical Report 68-65-FL, U.S. Army Natick Research and Development Laboratories.

Toumy, J.M. and L.C. Hinnergardt. 1968b. Effect of headspace oxygen on the quality of freeze-dried raw beef patties. Technical Report 69-54-FL, U.S. Army Natick Research and Development Laboratories.

Toumy, J.M., L.C. Hinnergardt, R.L. Helmer. 1969. Effect of oxygen uptake on quality of cooked, freeze-dried combination foods. Agric. Food Chem. 17(6): 1360.

Toumy, J.M., L.C. Hinnergardt, R.L. Helmer. 1970. Effect of storage temperature on the oxygen uptake of cooked, freeze-dried combination foods. Agric. Food Chem. 18(5): 899 .

Umbreit, W.W., R.H. Burris, J.F. Stauffer. 1964. Manometric Techniques, 4th Ed., Burgess Publishing Co., Minneapolis, MN.

Verhey, L.G.P. and W.L. Lammers. 1970. A method for the determination of the residual gas volume in dried milk products. Neth. Milk Dairy J. 24: 96.

Watanabe, H. and J.E. Leonard. 1957. Some performance data on a polarographic oxygen electrode. Beckman Reprint R-6133. Beckman Instruments.

Weaver, J.C., M.K. Mason, J.A. Jarrell, J.W. Peterson. 1976. Biochemical assay by immobilized enzymes and a mass spectrometer. Biochem. Biophys. Acta. 438: 296. 
Widomski, J. and W. Thompson. 1979. Applications of a new headspace gas chromatography device. Chromatography Newsletter. $7(2): 31$.

Woldring, S., G. Owens, D.C. Woolford. 1966. Blood gases: continous in vivo recording of partial pressures by mass spectrometry. Science 153: 885 . 


\section{LIST OF SYMBOLS}

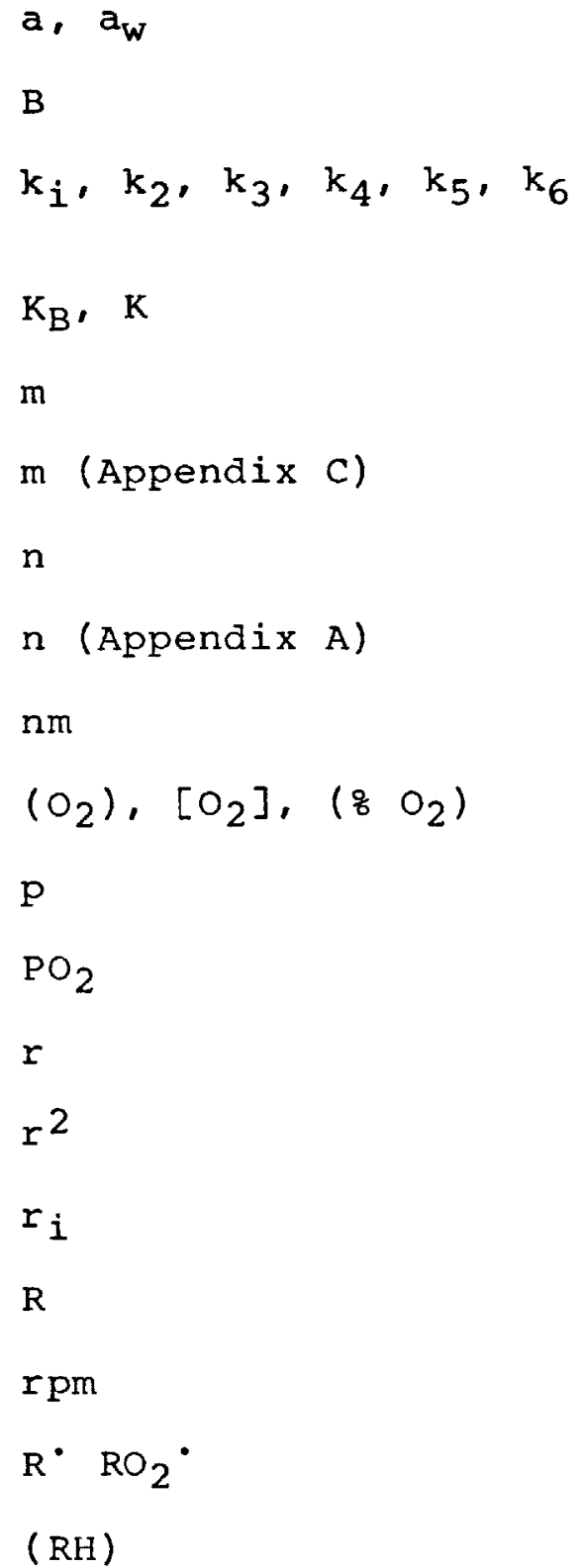

water activity

B.E.T. equation constant

rate constants for individual steps in BAS.

bimolecular rate constant

moisture content per $100 \mathrm{~g}$

meters

number of samples

moles of $\mathrm{O}_{2}$ (ideal gas equations)

nanometers

oxygen concentrations ( $\%$ )

pressure

partial pressure of oxygen

correlation coefficient

coefficient of determination

rate of initiation

universal gas constant

revolutions per minute

free radicals

concentration of unoxidized

fatty acid.

concentration of hydroperoxide

surface area of powder

time

temperature

moisture content per gram 
$\mathrm{V}_{\mathrm{m}}$

W

$\overline{\mathrm{x}}$

$\left(x_{i}, y_{i}\right),\left(x_{i}, y_{i}\right)$ monolayer value

weight of sample

mean sample oxygen concentration

data pairs 